\title{
Fertility in Germany before and after the 2011 Census: Still no Trend Reversal in Sight
}

\author{
Olga Pötzsch
}

\begin{abstract}
The population projections by the German Federal Statistical Office show a likely decrease in the number of births in the 2020s. This development will be the result of a declining number of prospective mothers combined with an assumed continued low fertility rate. Given the available empirical findings prior to the 2011 census, there was no indication that a possible distinct rise in the fertility rate in the next decade would compensate for the declining number of potential mothers. However, the 2011 census led to revisions in the population size, age structure and consequently in relative fertility measures such as period and cohort fertility rates.

The objective of this article is to quantify the effects of the 2011 census on these fertility statistics and to check the validity of previous findings for fertility trends on the census-adjusted data basis. A special focus is laid on analyses of the cohort fertility and the consequences of ever-later entry into motherhood on the completed fertility and on parity distribution. Using numerous findings, we will show that a continuous rise in the completed fertility in the coming two decades cannot be realised without a reversal of fertility behaviour. A greater increase in fertility from the age of 30 onwards would be necessary to offset the decrease in fertility for ages under 30 - a trend which intensified with cohort 1974 - and thereby stabilise the total cohort fertility rate at a relatively low level between 1.5 and 1.6 births per woman. A rise and subsequent stabilisation of the total cohort fertility rate at the level of at least 1.6 births per woman would, additionally, necessitate a trend reversal in the development of childlessness and distinct changes in birth timing.
\end{abstract}

Keywords: Postponement and recuperation of births · Development of fertility rates $\cdot$ Total fertility rate $\cdot$ Cohort fertility $\cdot$ Childlessness $\cdot$ Census

\section{Introduction}

Following the 2011 census, which enabled adjustments to population projections for the first time in nearly a quarter century, demographic statistics also need to be reassessed. This also applies to the relative fertility measures, which, in addition 
to the absolute numbers, also describe the general development of fertility. They show the proportion of the actual number of children born to the number of potential mothers, i.e. women of childbearing age (in this case between 15 and 49 years). Adjusted population figures thus have an influence on fertility rates via the female population (macro data level) while also forming the population for extrapolating the microcensus and thereby influencing its weighted sample results (micro data level). The microcensus is the largest random sample survey of private households in Germany which gathers information about the number of children per woman born until the time of survey every four years since 2008. This data provides the basis for the distribution of female cohorts according to parity as well as for the development of childlessness.

This article examines birth trends incorporating the effects of the 2011 census on the main fertility measures. Emphasis is put on relevant aspects of fertility behaviour, which, from today's perspective, can also be significant for future fertility developments. Respective findings will be analysed here and combined to form a comprehensive picture of fertility.

After presenting the data sources and methods in the second section of the article, we describe effects of the 2011 census on the measurement of fertility in the third section. The choice of indicators employed is aligned to internationally common and widely used fertility indicators. These include period-related figures such as the number of women in the respective cohorts who are potential mothers and thus belong to the so-called "population at risk" as well as the age-specific and total fertility rates. In the cohort perspective, these are mainly the cohort fertility rate and cumulated fertility rates at a selected age as well as the parity distribution among the female cohorts. The snapshot of the fertility level in the year 2011 before and after the census is the starting point for the adjustment of fertility trends and the assumptions for population projections.

In the fourth section, current fertility trends and assumptions regarding future fertility developments based on new data after the census are discussed. While the number of prospective mothers in the next two decades will largely result from the previous demographic development, the future fertility rate has to be estimated on the basis of findings about fertility behaviour. One approach chosen for this is based on studies of cohort fertility. The central question is how the completed fertility rate develops under the influence of a continued delay of first births. The following analyses build upon the studies on the childbearing postponement and recuperation (Frejka/Calot 2001; Frejka/Sobotka 2008; Sobotka et al. 2011; Frejka 2012; Pötzsch 2013), about interaction between parities and their impact on the cohort fertility (Statistisches Bundesamt 2009, 2013; Sobotka 2011; Bujard/Lück 2015a) as well as on the development of childlessness (Dorbritz/Ruckdeschel 2007; Sobotka 2011; Konizka/Kreyenfeld 2013; Statistisches Bundesamt 2013, 2015a; Beier et al. 2012; te Velde et al. 2012).

Preliminary estimations of the completed fertility published so far go back to the cohorts born in the mid- to late 1970s (Goldstein/Kreyenfeld 2011; Pötzsch 2010a, 2013; Myrskylä et al. 2013; Statistisches Bundesamt 2015a). There is no doubt that the declining trend among women born in the late 1960s ends and is replaced by a 
slight increase in the completed fertility until cohort 1973. Afterwards, the cohort fertility in Western Germany appears to stagnate while it probably increases further in Eastern Germany (cf. Pötzsch 2013: 95-97; Myrskylä et al. 2013, Table 2 and Appendix Fig. 1). In the following, we will analyse the overall fertility trends in Germany on the basis of the census-adjusted results and discuss perspectives of the fertility development up to the 1984 cohort.

\section{Data and methods}

The relative fertility indicators usually refer to the so-called average population. Unlike the reference day population, the average population considers variations in the population size during the year, which usually and mainly are caused by migration. The average population therefore offers a better approximation to the "population at risk" as reference for fertility rates. The population at risk is an estimation of the lifetime in which this population was exposed to "the risk of a birth" (Luy 2016: 123125). To calculate the age-specific fertility rates, we also need the average population broken down by single ages. The official statistics use two calculation methods for this: completed age and birth years (cohort). In this article we use the population broken down by cohorts because it permits a long-term view. Results according to completed age are only available from 2000 onwards.

For clarification's sake, the cohort fertility is usually understood as the completed number of children that a female cohort had born on average. The cohort total fertility rate (CTFR) is calculated as the sum of the age-specific fertility rates of a female cohort ascertained in the calendar years in which this cohort was in the ages between 15 and 49 years. The age-specific fertility rate is a ratio between the number of births by mothers of a cohort $c$ at a certain age, $B_{c}(x)$, and the number of all women of this cohort at the same age, $P_{c}(x)$, in one calendar year.

$$
\text { CTFR }=\sum_{\alpha}^{\beta} f_{c}(x)=\sum_{\alpha}^{\beta} \frac{B_{c}(x)}{P_{c}(x)}
$$

The additive character of the CTFR allows us to subdivide these according to age spans by varying the parameters $\alpha$ and $\beta$. In this article, this character will be used to illustrate the different age-specific trends in the younger and older fertile ages as well as the interaction between the postponement and recuperation of births. This is done, for example, by adding both the age-specific fertility rates of the female cohorts aged between 15 and 29 years and of those aged between 30 and 49 years. The sum of the two results leaves us with the CTRF:

$$
\sum_{15}^{29} f_{c}(x)+\sum_{30}^{49} f_{c}(x)=\sum_{15}^{49} f_{c}(x)=\text { CTFR }
$$

The analysis of the cohort fertility rate in Section 4.1 is based on an approach by Frejka and Calot (2001) and its further development by Sobotka et al. (2011). This 
approach for calculating the recuperation index was simplified here and slightly modified in order to present the development of postponement and recuperation of fertility as clearly as possible. The two processes are observed separately and are compared with one another. Beforehand, the deviations between the cumulative age-specific fertility rates of the observed cohort and the cohort selected as a reference were measured for each age year. The greatest deviation marks the "trough" at which the cumulative fertility of the observed cohort differs the most from the reference cohort. Once the trough is crossed, the recuperation phase begins. If the "postponed" births are not completely recuperated, there is a residual deviation between the completed fertility rates at the end of the fertile phase. However, if the deviation at the trough is compensated or overcompensated for by recuperation at an older age, then the cohort total fertility rate of the observed cohort will be the same or even higher compared to the completed fertility of the reference cohort. (For more details on the basic reference model and application examples for Germany see Sobotka et al. 2011, Section 3.2, and Pötzsch 2013).

Theoretically, the completed fertility of the female cohorts could also be ascertained based on micro data, i.e. the information about the number of children born provided by respondents in the microcensus. The total number of children born to women of a cohort would be divided by the number of women in that cohort. This average fertility rate is, however, only comparable with the CTFR to a limited extent. For one, these two indicators refer to different populations (Pötzsch 2010b: 171-172; Kreyenfeld et al. 2012: 394). For example, because of migration and mortality it is highly probable that the composition of the 1950 female cohort at the time of the microcensus survey in 2012 was a different one than in the years 1965 to 1999, from which the 35 age-specific birth rates of this cohort (between the ages of 15 and 49) originated. Secondly, the microcensus results are marked by a sampling error and may be biased because of non-responses. An imputation method is employed in order to minimise systematic biases caused by non-responses (Statistisches Bundesamt 2009, 2013). Nonetheless, some of the cases remain unknown. In the 2012 microcensus, this mainly affects the distribution of mothers according to the number of children born. Hence, special attention needs to be paid when calculating average numbers of children per woman. If only known cases are included, the number of mothers without any information on the number of children is distributed proportionally to all parities including the parity 0 (i.e. no child). This approach increases the weight of the childless in this average figure. In addition, the percentage of missing information about the number of children born varies depending on the cohort, e.g. between 1 percent and 8 percent in the 2012 microcensus, which further limits the comparability of the results among the cohorts.

In spite of these limitations, the microcensus is the main data source for ascertaining the rate of childlessness and the distribution of mothers according to the number of children. The microcensus is also used to assess the effects of the census-based revision of the population on the cohort fertility rate. To do so, the results of the 2012 survey are compared based on the extrapolations before and after the census. Since the considered results refer to the same cohorts and are based on the same sample, the average fertility rate per cohort before and after the census can 
also be compared. In this case it is less a question of the average number of children per woman than of the extent of the shifts caused by the new extrapolation.

For many indicators, it remains advisable to portray the development not just for Germany as a whole, but also for Western and Eastern Germany. In spite of converging trends, differences in women's fertility behaviour remain significant (Statistisches Bundesamt 2013). Although it is geographically located in Germany's east, Berlin is not counted as "Eastern Germany" since Berlin's fertility patterns are more similar to Western Germany's. Due to its great weight, incorporating Berlin into the results for Eastern Germany would dilute the eastern German fertility trends and bias the comparison with the western part. Berlin is, however, included in the results for Germany as a whole.

\section{Effects of the census on the main fertility figures}

\subsection{Female population as reference value for the fertility rates}

The total number of potential mothers - i.e. women between the ages of 15 and 49 - in the year 2011 dropped in the census-adjusted population by 321,000 , or 1.8 percent (Table 1). In Western Germany, the revision was at only -1.5 percent and thus lesser than in former Eastern Germany at -2.0 percent. While the number of women of German nationality remained almost unchanged, there was a greater need for revisions among women with foreign citizenships. The number of women with for-

Tab. 1: Women aged between 15 and 49 years - revisions after the census 2011

\begin{tabular}{|c|c|c|c|c|}
\hline \multirow[t]{3}{*}{ Region } & \multicolumn{2}{|c|}{ Average annual population in 2011} & \multicolumn{2}{|c|}{$\begin{array}{c}\text { Changes after the } \\
\text { census }\end{array}$} \\
\hline & BEFORE the census & AFTER the census & absolute & relative \\
\hline & \multicolumn{2}{|c|}{1,000 People } & & $\%$ \\
\hline \multicolumn{5}{|l|}{ Women only } \\
\hline Germany (as a whole) & 18,209 & 17,888 & -321 & -1.8 \\
\hline Western Germany ${ }^{1}$ & 14,810 & 14,589 & -221 & -1.5 \\
\hline Eastern Germany ${ }^{1}$ & 2,554 & 2,504 & -50 & -2.0 \\
\hline \multicolumn{5}{|l|}{ German women } \\
\hline Germany (as a whole) & 15,959 & 15,895 & -64 & -0.4 \\
\hline Western Germany ${ }^{1}$ & 12,811 & 12,797 & -14 & -0.1 \\
\hline Eastern Germany ${ }^{1}$ & 2,461 & 2,429 & -32 & -1.3 \\
\hline \multicolumn{5}{|c|}{ Women with foreign citizenship } \\
\hline Germany (as a whole) & 2,250 & 1,993 & -257 & -11.4 \\
\hline Western Germany ${ }^{1}$ & 1,999 & 1,792 & -207 & -10.3 \\
\hline Eastern Germany ${ }^{1}$ & 92 & 75 & -18 & -19.0 \\
\hline
\end{tabular}

${ }^{1}$ without West Berlin or respectively without East Berlin.

Source: Statistisches Bundesamt, intercensal population updates, own calculations 
Fig. 1: $\quad$ Women aged between 15 and 49 years $^{1}$ - relative changes of the average annual population in 2011 after the census
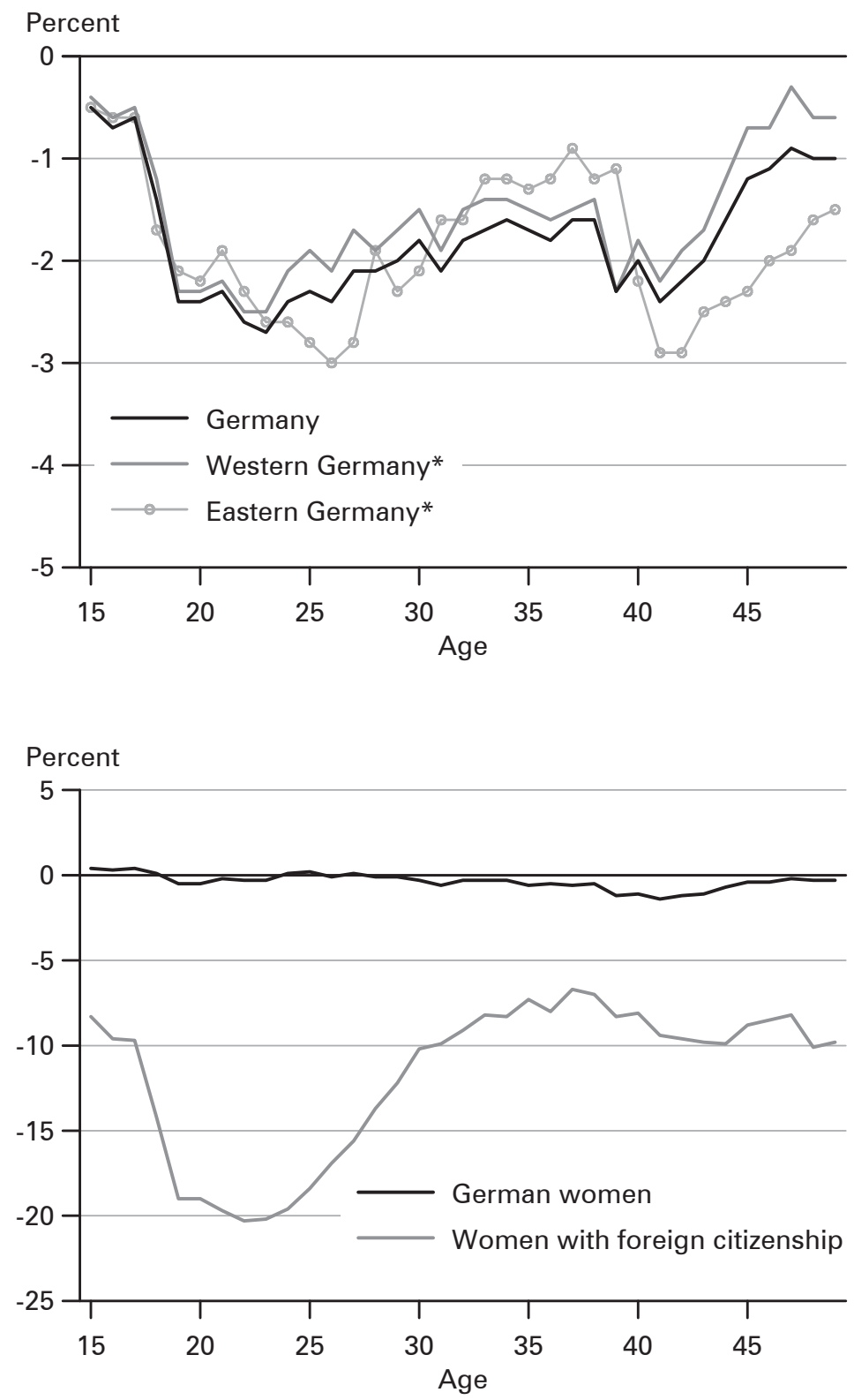

${ }^{1}$ Age reached at the end of 2011.

* without West Berlin or respectively without East Berlin

Source: Statistisches Bundesamt, intercensal population updates, own calculations and design 
eign citizenships between the ages of 15 and 49 had been corrected by - 11.4 percent when looking at Germany as a whole, in Western Germany by -10.3 percent and in Eastern Germany by -19.0 percent. Therefore, the percentage of women with a foreign citizenship among all women of childbearing age dropped from 12.4 percent to 11.1 percent.

Changes in the individual birth cohorts within the childbearing phase are relevant for the age-specific fertility rates. Germany-wide there is a relatively distinct pattern (Fig. 1). The revision of the number of women between the ages of 19 and 27 was above average (to -2.5 percent). As shown in the lower segment of Figure 1, these changes are mostly due to the revisions among the women of foreign nationality. By contrast, the deviations among women of German nationality are negligibly low. In Eastern Germany, there has been a greater need for revisions concerning the number of women aged 40 to 45 years. Since the number of births among this age group is rather low, it seems resonable to suggest only minor effects on the completed fertility rate in 2011. At the same time, this might indicate that out-migration

Fig. 2: Women aged between 15 and 49 years ${ }^{1}$ - relative changes of the average population size in 2011 after the census, in the federal states

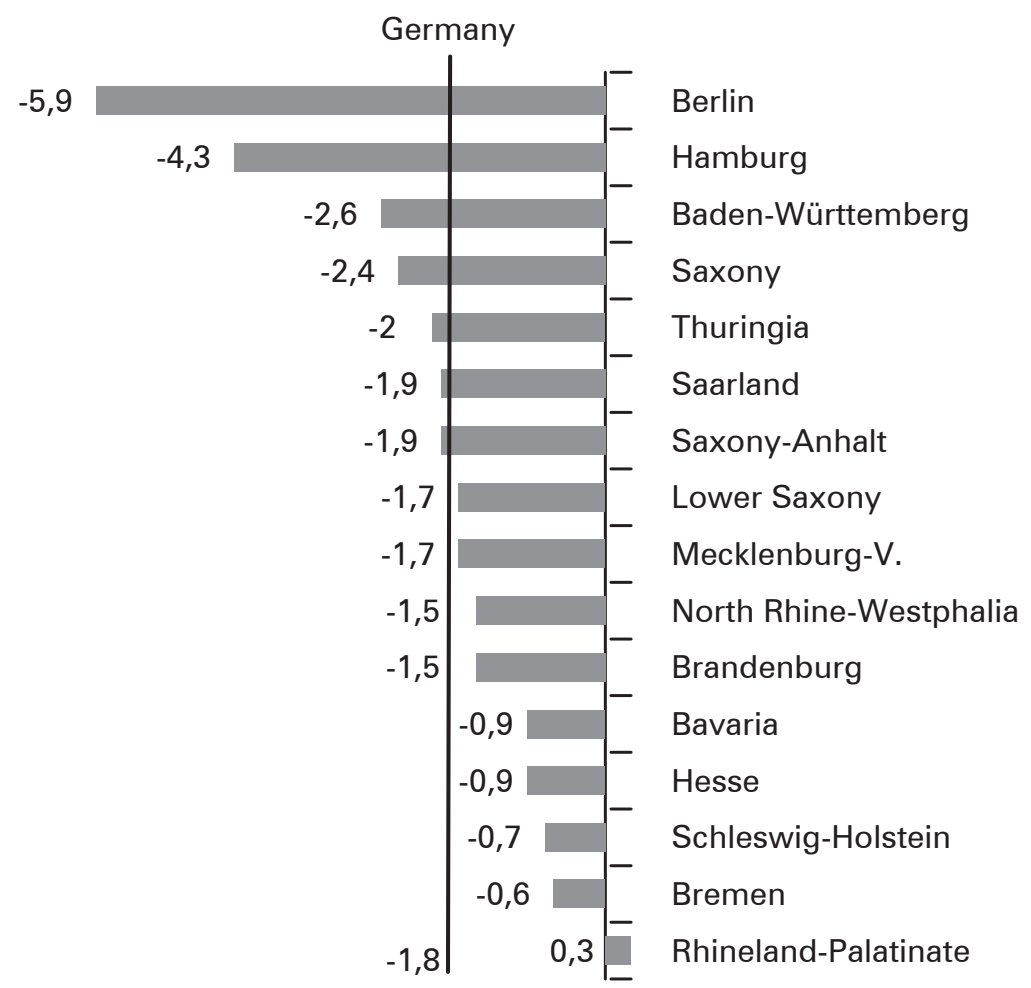

${ }^{1}$ Age reached at the end of 2011.

Source: Statistisches Bundesamt, intercensal population updates, own calculations and design 
of young women then aged between 20 and 25 years had not been fully included in population updates directly after German reunification - due to missing registration data. Therefore, the number of women of respective cohorts might have been slightly too high.

For the cohort measures, such as the completed fertility, it is also important how the revisions affected the older female cohorts. The adjustments among the cohorts 1930 to 1961 - birth cohorts for which fertility rates are available - were far lesser, with an average of 0.9 percent, than among the younger women. We cannot preclude that the uncertainties were in part greater in each of the years between the censuses when the women of these cohorts were both of childbearing age and in their "mobile" phase. Nonetheless, the low deviation at the time of the census 2011 is an important indication that the cohort-specific fertility rates apparently do not contain any major biases.

The need for revisions varied in the federal states between +0.3 percent in Rhineland-Palatinate and 5.9 percent in Berlin (Fig. 2). The city-states of Berlin and Hamburg recorded the greatest deviations between the census results and the population updates between the censuses.

\subsection{Effects of the census on the $\mathbf{2 0 1 1}$ fertility indicators}

When calculating the fertility rates, the census adjustment means that only the reference - the female population - in the denominator of the formula (1) changes, while the number of births in the numerator remains unchanged. The census revision therefore affects the relative birth figures in a comparable ratio to the revision of the number of women, but with reversed signs. From the demographic perspective, the age-specific and aggregated fertility rates are particularly interesting, such as the total fertility rate (from the period perspective) and the cohort total and cumulated fertility rate up to the respective age (from the cohort perspective).

In 2011, when incorporating the census revision, the total fertility rate in Germany was 1.39 births per woman (Table 2). This figure was 2.0 percent higher than before the census (1.36 births per woman). In Western Germany the change was 1.8 percent (from 1.36 to 1.38 births per woman) and in Eastern Germany 2.0 percent (from 1.43 to 1.46 births per woman).

For women of German nationality, the effects of the population revisions on the total fertility rate, with an average of 0.3 percent, were hardly noticeable. Among women of foreign nationality, in contrast, it rose by 15 percent from 1.58 to 1.82 births per woman.

The revisions of the birth rates in the federal states ranged from 0.5 percent in Rhineland-Palatinate to 6.3 percent in Berlin. Besides Berlin, the federal states with a particularly great need for revisions included Hamburg (4.6 percent), partly due to the high percentage of women with foreign citizenships in the female populations in both city-states (approximately 16 percent each among women between the ages of 15 and 49). Since, according to the census, the foreign population dropped considerably, the fertility rates in the city-states rose to an above-average degree. 
Tab. 2: $\quad$ Total fertility rate 2011 - necessary revisions after the census 2011

\begin{tabular}{|c|c|c|c|c|}
\hline Region/Nationality & $\begin{array}{l}\text { BEFORE the } \\
\text { census }\end{array}$ & $\begin{array}{l}\text { AFTER the } \\
\text { census }\end{array}$ & $\begin{array}{r}\mathrm{Ch} \\
\text { absolu }\end{array}$ & $\begin{array}{l}\text { es } \\
\text { elative }\end{array}$ \\
\hline & Chi & ren per woman & & $\%$ \\
\hline Women (total) & & & & \\
\hline Germany & 1.36 & 1.39 & 0.03 & 2.0 \\
\hline Western Germany ${ }^{1}$ & 1.36 & 1.38 & 0.02 & 1.8 \\
\hline Eastern Germany ${ }^{1}$ & 1.43 & 1.46 & 0.03 & 2.0 \\
\hline German women & & & & \\
\hline Germany & 1.33 & 1.34 & 0.00 & 0.3 \\
\hline Western Germany ${ }^{1}$ & 1.32 & 1.32 & 0.00 & 0.1 \\
\hline Eastern Germany ${ }^{1}$ & 1.43 & 1.45 & 0.02 & 1.2 \\
\hline Women with foreign citizenshi & & & & \\
\hline Germany & 1.58 & 1.82 & 0.24 & 15.0 \\
\hline Western Germany ${ }^{1}$ & 1.60 & 1.81 & 0.22 & 13.5 \\
\hline Eastern Germany ${ }^{1}$ & 1.48 & 1.82 & 0.34 & 22.8 \\
\hline Federal states & & & & \\
\hline Baden-Württemberg & 1.36 & 1.39 & 0.04 & 2.8 \\
\hline Bavaria & 1.34 & 1.36 & 0.01 & 1.0 \\
\hline Berlin & 1.31 & 1.40 & 0.08 & 6.3 \\
\hline Brandenburg & 1.41 & 1.44 & 0.02 & 1.6 \\
\hline Bremen & 1.27 & 1.29 & 0.01 & 1.1 \\
\hline Hamburg & 1.26 & 1.32 & 0.06 & 4.6 \\
\hline Hesse & 1.39 & 1.40 & 0.01 & 0.6 \\
\hline Mecklenburg-Vorpommern & 1.42 & 1.44 & 0.02 & 1.5 \\
\hline Lower Saxony & 1.39 & 1.42 & 0.04 & 2.6 \\
\hline North Rhine-Westphalia & 1.36 & 1.39 & 0.02 & 1.8 \\
\hline Rhineland-Palatinate & 1.37 & 1.37 & 0.01 & 0.5 \\
\hline Saarland & 1.28 & 1.31 & 0.04 & 2.8 \\
\hline Saxony & 1.48 & 1.51 & 0.04 & 2.5 \\
\hline Saxony-Anhalt & 1.40 & 1.43 & 0.03 & 2.0 \\
\hline Schleswig-Holstein & 1.38 & 1.40 & 0.02 & 1.5 \\
\hline Thuringia & 1.41 & 1.44 & 0.03 & 1.9 \\
\hline
\end{tabular}

1 without West Berlin or respectively without East Berlin.

Source: Statistisches Bundesamt, Births statistics, own calculations

The age-specific fertility rates for all women only changed slightly; therefore, the distribution of fertility rates according to the age of the mother remained almost constant. The average childbearing age in Germany even after the census revision was 30.5 years, the median was 31 years. However, the highest fertility rate, that of the 31-year-olds, rose from originally 98 to 100 children per 1,000 women. In Western Germany and in Eastern Germany only a slight increase in the maximum frequency was recorded. 
Fig. 3: Age-specific fertility rate 2011 - necessary revisions after the census 2011
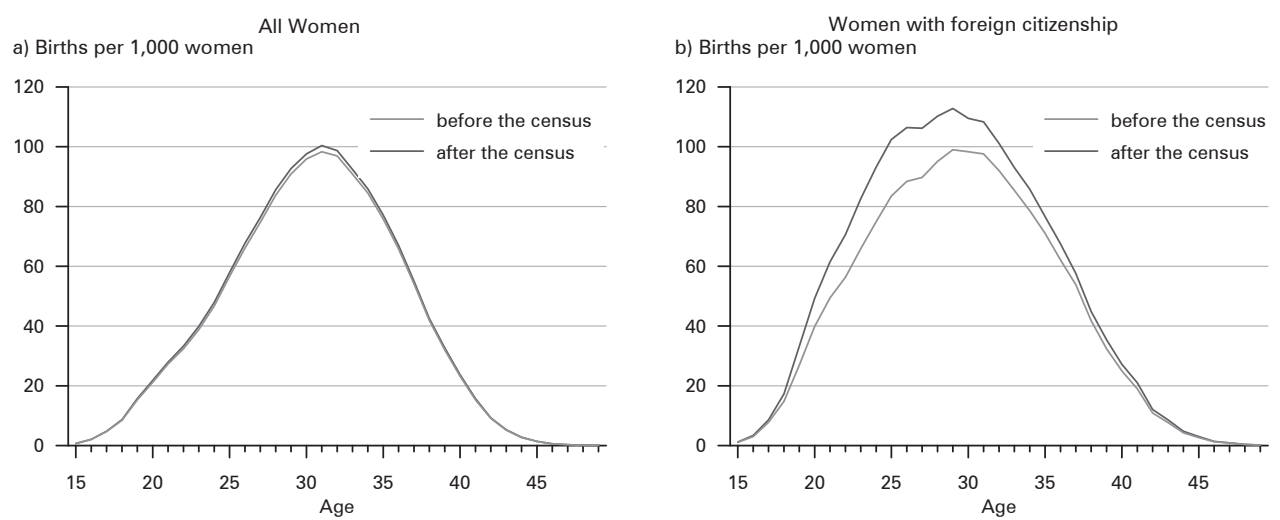

Source: Statistisches Bundesamt, Births statistics, own calculations and design

The age-specific changes among women of foreign nationality occurred in particular among those in their mid-twenties (Fig. 3). This led to a slight drop in the average childbearing age by 0.3 years to 29.3 years and in the median by 0.4 years to 29.6 years. The maximum fertility rate (at the age of 29) increased from 99 to 113 children per 1,000 women. These changes, however, have no relevant effects on the fertility of the women as a whole. Figure 3(a) clearly illustrates that they merely lead to a marginal shift in the of the age-specific fertility rates.

\subsection{Effects of the census on the time series of the TFR}

The census-based adjustment does not result in a fundamental shift in the levels of the long-term development of the total fertility rate. The curves shown in Figure 4 contain the figures for the year 2011 both before and after incorporating the census results. The new, adjusted figures follow the curves without any significant leaps. Even when we compare the annual changes in the total fertility rate it is clear that the "census effect" is no greater than the usual annual fluctuations.

Among women of German nationality, the "census effect" on the development of the TFR is negligible. It remains at the low level of 1.34 births per woman rather than 1.33 births per woman before the census (Fig. 5). Among women of foreign nationality, however, the census adjustment led to a visible shift in the level of the TFR for 2011 from 1.58 to 1.82 births per woman. The consequence is that a trend revision is necessary and that the assumption of a rapid convergence of the fertility rate of female foreigners to that of German women must be qualified. At 11 percent, the decrease in the total fertility rate of women with a foreign nationality between 1991 and 2011 is, according to the new findings, only half as strong as originally presumed (22 percent). In 2012 and 2013 the fertility rate among women of foreign nationality stagnated further to the level of about 1.80 births per woman. The 
Fig. 4: Total fertility rate 1990 - 2013 with „census-effect" in 2011 Births per woman

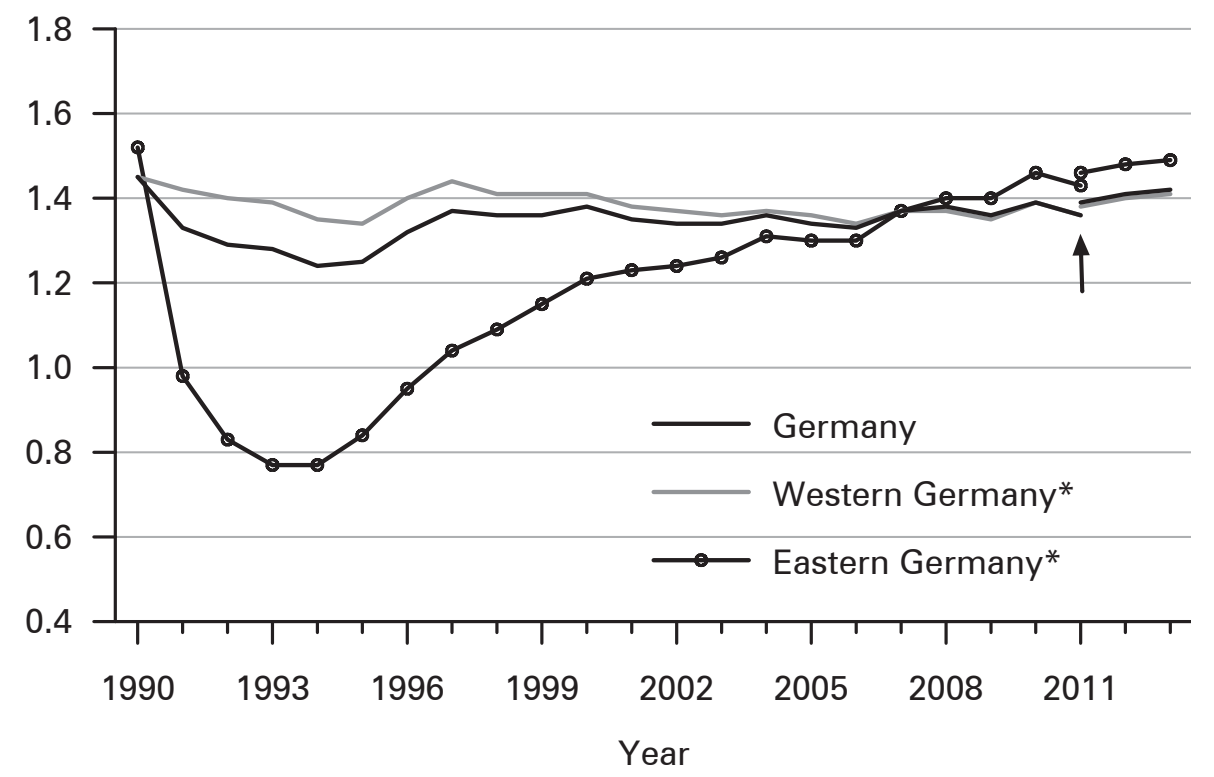

Fig. 5: Total fertility rate according to nationality 1991 - 2013 with "censuseffect" in 2011

Births per woman

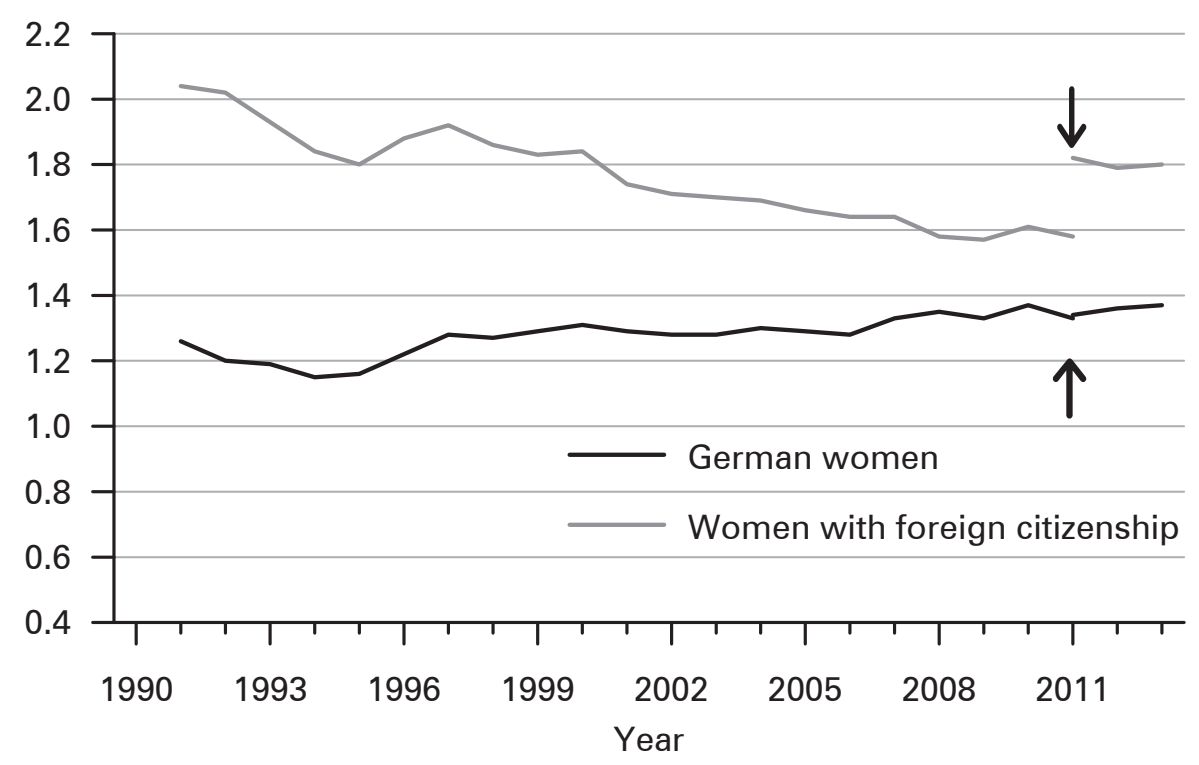

* without West Berlin or respectively without East Berlin.

Source: Statistisches Bundesamt, Births statistics, own calculations and design 


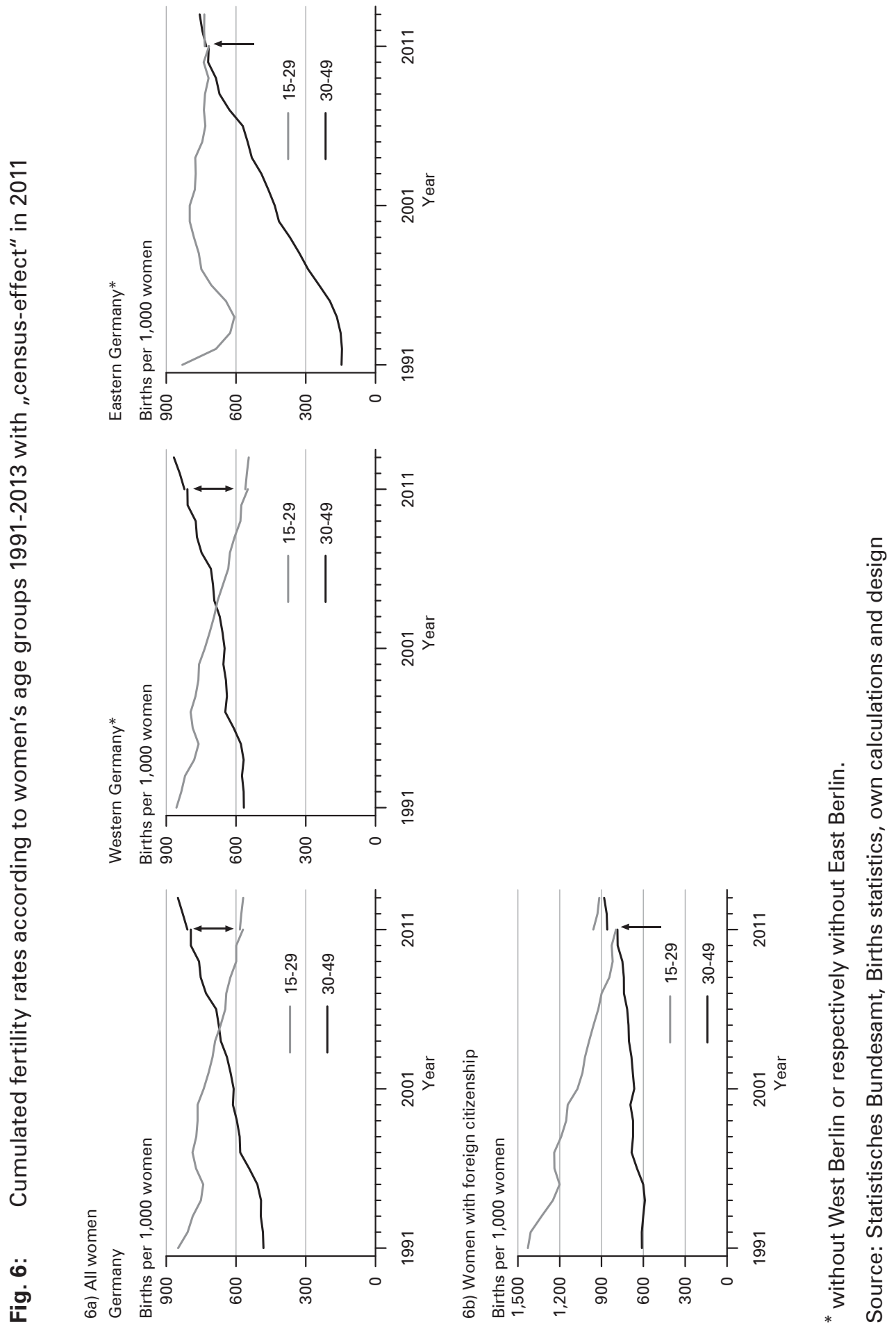


percentage of births by mothers with a foreign nationality among all children born remained a steady 17 percent to 18 percent since 1996.

Long-term age-specific trends are decisive for the development of the total fertility rate. They can basically be illustrated using only two age groups. As Figure $6 a$ shows, the birth rate among women under age 30 drops while the fertility of the 30 to 49 -year-olds rises. After the census, there is a slight revision for the younger age group for the year 2011 but even the revised TFR for 2011 is lower than in 2010. Thus, the trend in the fertility rate of 15 to 29 -year-olds is still declining even after the census. The adjusted fertility rate among the older age group fits perfectly into the previous development and does not disturb the curve progression. This is true for Western Germany and - with a minor variation in the curve progressions - also for Eastern Germany.

The census-based revision resulted in a leap in the curve progression of the fertility rate among younger women of foreign nationality (Fig. 6b). The accumulated fertility rate of the 15 to 29 -year-olds in 2011 rose by 20 percent. However, there is apparently still a declining trend. Among the age group of the 30 to 49 -year-olds, the revisions are comparatively low at +9 percent. The main reason for the falsely estimated decrease in the birth rate among women of foreign nationality is thus due to the fertility rates of the 20 to 29 -year-olds. The apparent systematic overestimation of the number of women with foreign citizenships, in particular for this very mobile age group, led to much too low figures.

\subsection{Effects of the census on the cohort fertility rate}

In Germany, the cohort total fertility rate per woman is available for the cohorts from 1930 onwards. ${ }^{1}$ A cohort-by-cohort back-calculation would be necessary to revise the age-specific cohort figures after the 2011 census. However, the census only caused a slight change in the number of women in the cohorts until the early 1960 s (average 0.9 percent) so we can assume a marginal bias to the cohort figures and therefore, a time-consuming and highly uncertain back-calculation does not seem worthwhile. Among the cohorts at childbearing age, in particular the 1980s and 1990s cohorts, the number of women dropped a bit more after the census than among the older cohorts. But the changes in the individual age-specific fertility rates are also only minor as already shown in Section 3.2. The cumulated cohort fertility rates of the women in their fertile ages therefore only slightly changed after the census.

1 Cohort fertility, in this case, refers to all women. A separate analysis for German women and women of foreign nationality does not seem advisable, mainly because the foreign population constantly changes due to migration and their cohorts are subject to difficult-to-control exogenous influences. A cohort-specific analysis would be possible with restrictions for German women but since it hardly changed after the census, such an analysis would not provide any additional information with regard to cohort fertility among Germans. 
Fig. 7: Completed or achieved average number of children per woman according to birth cohorts - results based on the microcensus 2012 according to the new (after the census) and the old (before the census) extrapolation

Completed average number of Achieved number of children until 2012 children

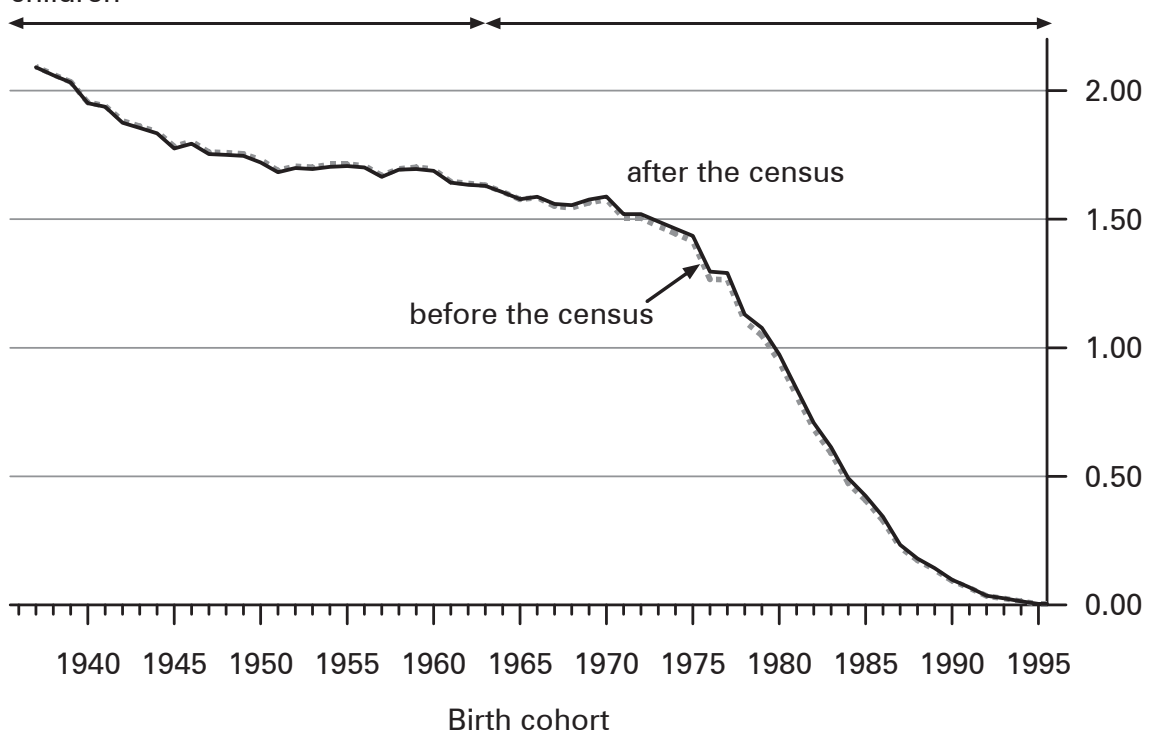

Source: Statistisches Bundesamt, Microcensus 2012, own calculations and design

Fig. 8: Absolute differences of completed or achieved average number of children per woman according to birth cohorts between the results of the microcensus in 2012 with the new (after the census) and the old extrapolation (before the census)

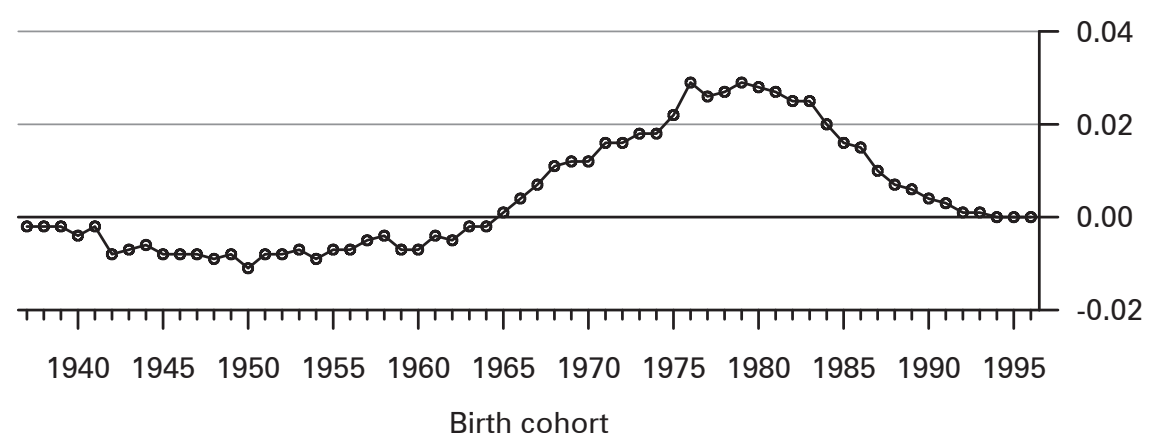

Source: Statistisches Bundesamt, Microcensus 2012, own calculations and design 
The microcensus is another possibility for checking the census impacts on the cohort fertility rate (Statistisches Bundesamt 2013). The two questions about children born are asked in the microcensus every four years. The last survey took place in 2012. The results of the 2012 microcensus published so far were based on the old extrapolation that did not yet incorporate the census revisions. The results from the new census-adjusted extrapolation are now also available and enable us to make a comparison with the results from the old extrapolation. In the following, we will compare these for the average number of children per woman (see Section 2) and for the distribution of the female cohorts according to number of children born (parity).

The development of the average number of children per woman is shown in Figure 7. For the cohorts of 1963 and older this development is completed, and for the younger cohorts only shown until 2012. The differences between the results according to the old (dotted line) and to the new (solid line) extrapolation are barely perceptible to the eye. The absolute differences are, as Figure 8 reveals, minor. The highest deviations are the almost 30 children per 1,000 women in the 1976 to 1981 cohorts.

Among the Western German female cohorts, the differences are similar to those for all women in Germany. In Eastern Germany, the average number of children among the young cohorts after the census rose a little more. In the 1976 to 1983 cohorts the deviations are 40 to 60 children per 1,000 women but these differences are lesser than the doubled absolute standard error and are therefore within the 95 percent confidence interval (Statistisches Bundesamt 2013: 66). Among the older cohorts from 1964, in contrast, the deviations among the Eastern German women are negligible.

The basis of the average number of children is the respective structure of the women of one cohort according to parity distribution. The interaction between the parities influences the completed fertility rate. The new extrapolation incorporating the census results only caused minor changes to the parity distribution. The upper part of Table 3 shows the percentage parity distribution of the cohorts according to the new extrapolation including the census-adjusted population. The lower section of the table shows the differences to the results of the "old" extrapolation. These tend to show a somewhat lower rate of childlessness and somewhat higher percentages of mothers with one or two children. The individual differences are, however, very slight and only marginally alter the previous basic findings concerning the parity distribution of the female cohorts.

\subsection{Intermediate conclusions}

According to the 2011 census, the female population of childbearing age was 321,000 lower than indicated by intercensal population updates. Therefore, the fertility indicators based on the number of women or on the extrapolated sample results of the 2012 microcensus only slightly changed. The 2011 total fertility rate increased by about 2 percent from 1.36 to 1.39 births per woman. With regard to long-term agespecific trends, the census-based revision was within the range of average annual 


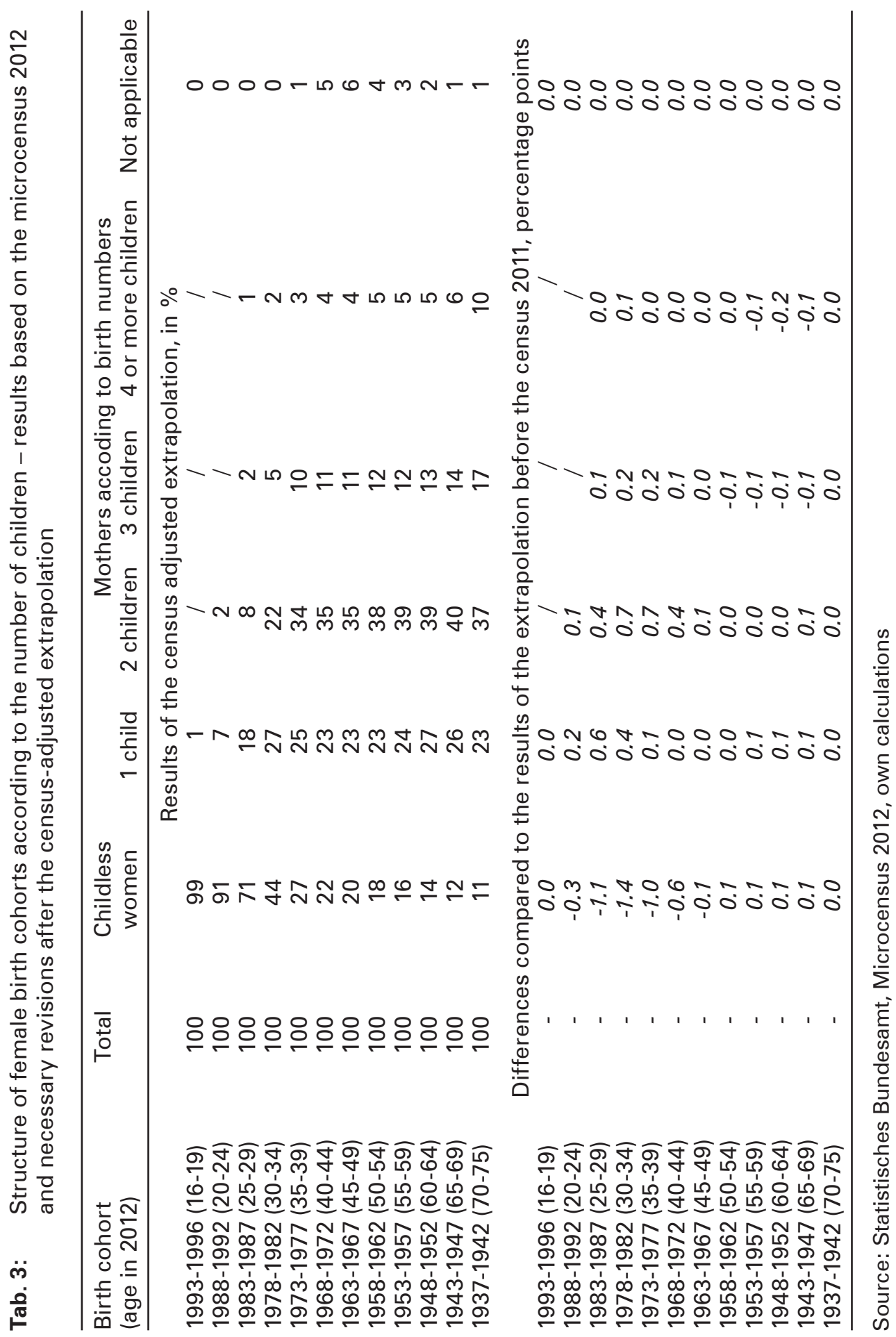


fluctuations. The effects of the 2011 census on the cohort fertility rate were also minor. The census-based adjustment had varying effects on the birth rates according to nationality. While the total fertility rate of women of German nationality remained nearly unchanged at 1.34 births per woman, it rose significantly among women of foreign nationality from 1.58 to 1.82 births per woman. This revision demands that previous findings on the fertility of women with foreign citizenship be re-examined. However, the influence of women of foreign nationality on total fertility trends has been rather low so far.

\section{Development of the cohort fertility rate in Germany}

The comparison of the main indicators showed that the general demographic picture of fertility developments largely remained the same after the 2011 census. The fertility studies can therefore be continued without major revisions. But what is the essence of this picture? In the following, we will attempt to approach this question by supplementing the results based on the data from the ongoing fertility statistics with the results of the 2012 microcensus. When put into context, these findings offer us insights into the principle features of fertility behaviours and an outlook on future fertility developments.

\subsection{No stable increase in cohort fertility rate foreseeable}

On average, women born in the 1930s - mostly the mothers of the so called "babyboom generation" - had more than two children (Fig. 9). Their family formation phase coincided with the economic upswing of the 1950s and 1960s. Yet, within the 1930s cohorts there are already indications of a steady decline in the completed fertility rate. It dropped particularly rapidly because of the decreases of higher order births - four or more children - between the cohorts of 1934 and 1944 (Statistisches Bundesamt 2009, 2013). Thereafter, the parity distribution of mothers largely stabilised but childlessness continued to increase. This has led, until today, to a less rapid yet steady decline in the cohort fertility rate. The 1964 cohort, with a total of 1.57 births per woman, is the most recent cohort to reach its fiftieth birthday and whose cumulated fertility rate is statistically considered completed.

It is already predictable that the completed fertility rate of the late 1960 s cohorts will drop further to approximately 1.49 births per woman. Afterwards, a slight recovery of the completed cohort fertility is anticipated (Pötzsch 2010a; Goldstein/ Kreyenfeld 2011; Sobotka 2011). One aspect contributing to this recovery is the stabilisation of the cohort fertility up to the age of 29 among the 1969 to 1973 cohorts. In addition, though, the fertility rates of these cohorts have continually risen for the ages of over 29. Together, these two effects created a favourable constellation, which did not, however, continue from the 1974 cohort. Between the 1974 and 1984 cohorts, cumulative fertility up to the age of 29 again dropped steadily. It remains to be seen how it will develop at an older age since these cohorts have not yet reached the end of their childbearing phase. Nonetheless, we can derive some indications by 
Fig. 9: $\quad$ Completed as well as cumulative fertility until the age of 29 by female birth cohorts

Births per woman

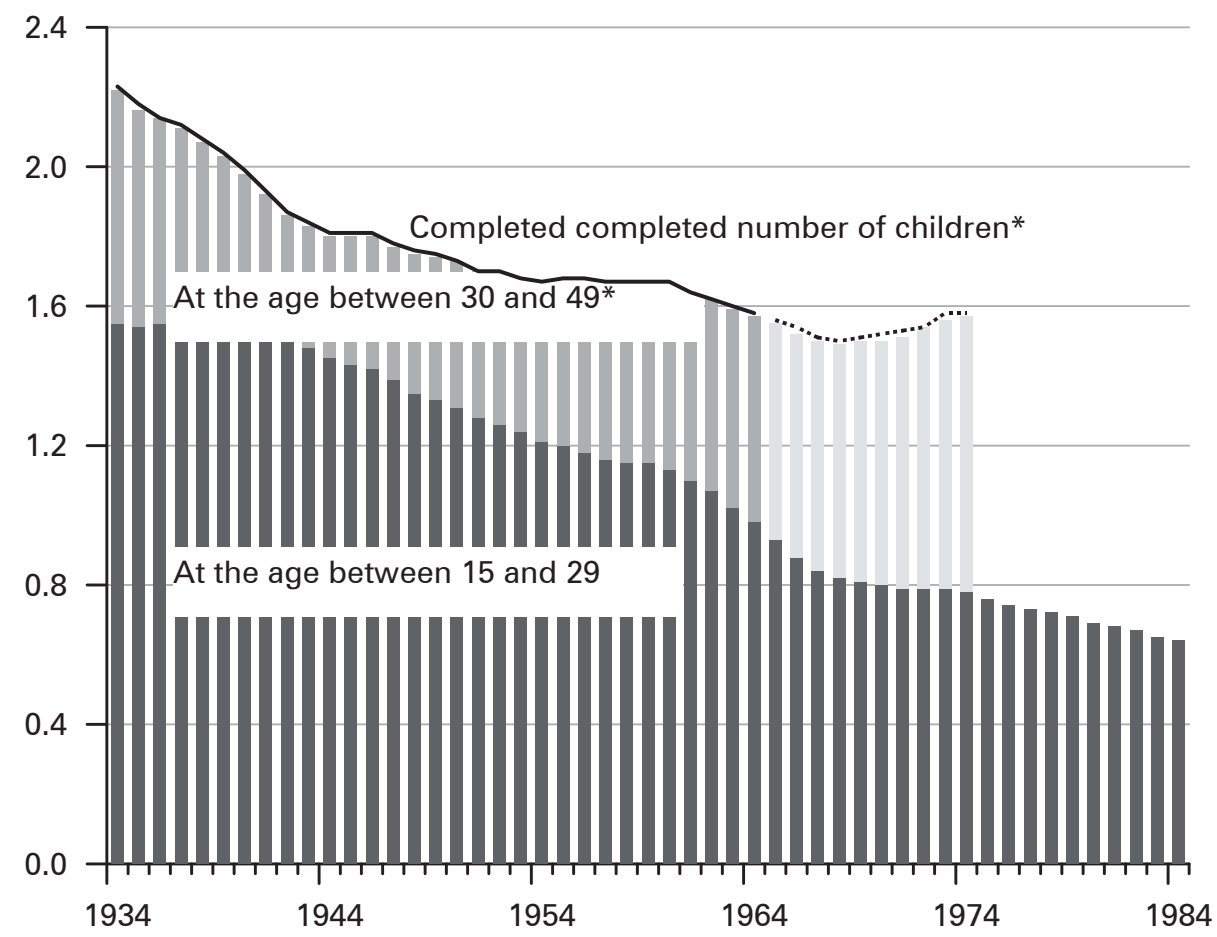

* Estimated figures for the cohorts 1965-1974.

Source: Statistisches Bundesamt 2013, own calculations and design

analysing the postponement and recuperation of births, the so-called P\&R process (Frejka//Calot 2001; Sobotka et al. 2011; Frejka 2012; Pötzsch 2013).

For P\&R analysis, we must understand cohort fertility as a process in which the earlier fertility biography of women significantly influences their future fertility decisions. Every female cohort has its own birth timing resulting from its fertility behaviour. For example, if most of the women of a cohort tend to have children in the younger childbearing phase, the cumulative fertility rises quickly, reaches its peak relatively soon and then remains almost constant (Fig. 10: 1944 cohort). If instead the majority of women of a cohort decide to have children in later ages, the cumulative fertility rises more slowly (1962 cohort). Whether the completed fertility remains lower than among the cohorts with a relatively "young" birth timing depends on whether all births that have been omitted at a young age are, in fact, recuperated in later ages. In Germany, the shift in timing to a later age has so far resulted in a trend towards a lower completed fertility (Pötzsch 2013). 
Fig. 10: Cumulative fertility rate of selected female birth cohorts by age

Births per 1,000 women

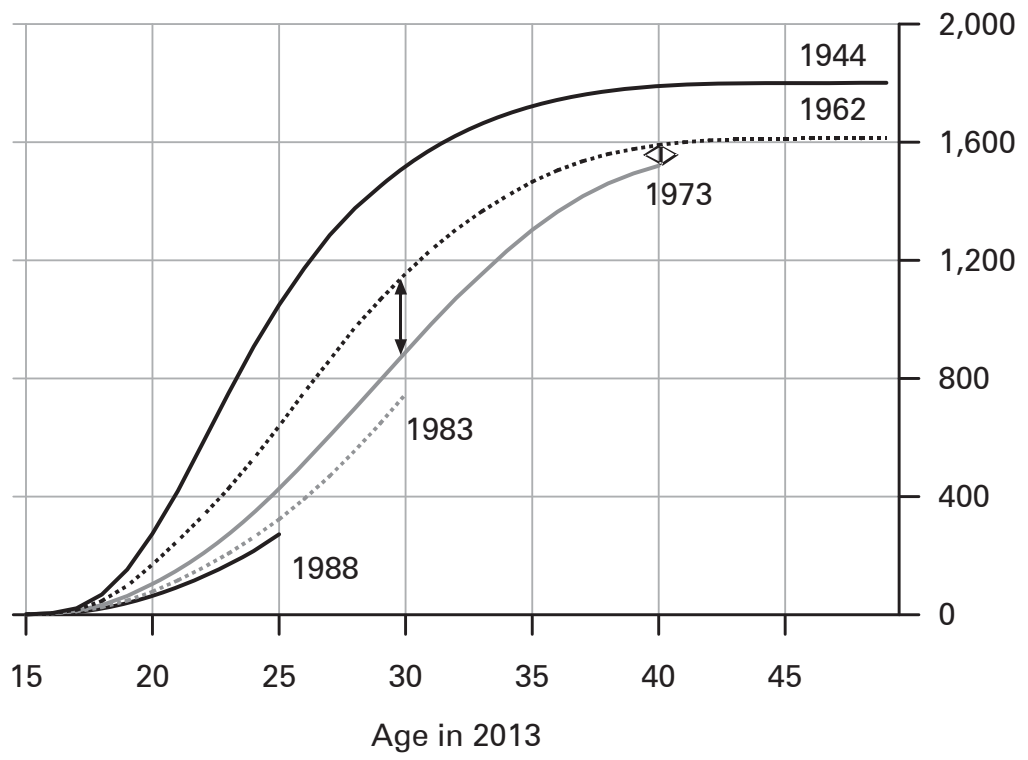

Source: Statistisches Bundesamt, Births statistics, own calculations and design

In comparison to the 1944 cohort, the 1962 cohort $^{2}$ gave birth later. The largest difference in cumulative fertility was reached in their late twenties. Although the distance between the two curves lessened, the extent of recuperation was not sufficient to compensate for the decrease in fertility at the young age and the CTFR fell by 0.2 . By the age of 28, the women born in 1973 had fewer births (on average) than the women of the 1962 cohort with a completed fertility of 1.61 . Starting at age 29 , they have recuperated the "postponed" births. By the age of 40 , the distance between the two curves lessened by three-fourths to 70 births per 1,000 women. They will probably not be able to completely close this gap at ages of 41 and above but it will be reduced considerably (cumulated cohort fertility rate at the ages of 41 to 49 is presently approx. 35 births per 1,000 women). The completed fertility rate of the 1973 cohort will be an estimated 1.57. The even younger 1983 and 1988 cohorts represent the current trends in cohort fertility rates. It becomes evident that ever fewer births are taking place during the younger fertile period.

In order to be able to assess effects of the most recent birth postponement on the completed fertility rate, we attempt to estimate the future recuperation potential

2 The 1962 cohort will be used as reference for further comparison since it is preliminarily the last completed cohort with a completed number of children of 1.6, for later cohorts the completed number of children will most likely drop below 1.6. 
using a graph (Fig. 11). For this purpose, we define the 1962 cohort with the CTFR of 1.61 as reference cohort. For every further cohort we calculate the difference between the cumulated cohort fertility rates of this cohort and the 1962 cohort (reference). These differences are negative because the birth rates decrease from cohort to cohort. They usually intensify up to the age of 29 years, which is the so-called trough, and then decrease, as shown previously using the example of the 1962 and 1973 cohorts in Figure 10. The phase until reaching the trough corresponds to the postponement of births; after this trough, the recuperation of births begins. In order to compare the postponement of births with the extent of recuperation, the age-specific fertility rates per cohort are added in the postponement and in the recuperation phase, respectively. The postponement phase ranges from 15 to 29 years. Multiple age limits are chosen for the recuperation phase in order to be able to make assertions even for the relatively young cohorts: from 30 to 35 , from 30 to 37 as well as from 30 to 40 years. For these phases we look at the deviations in the respective cumulative fertility rates of the 1963 to 1984 cohorts in comparison to the 1962 reference cohort (Fig. 11, upper part).

As expected, the deviations in the postponement phase are negative up to the age of 29 years while they are positive in the recuperation phase because the cohort fertility rate of the younger cohorts increases starting at the age of 30 . Here, the developments described above are portrayed in a different way: the decrease in the cohort fertility at a young fertile age was especially strong among the 1960s cohorts. In spite of an increasing fertility at the age of 30 and older, it can hardly be compensated for by the end of the fertile period. Instead, the remaining deviation at the age of 40 rose until the 1968 cohort, indicating a drop in the completed fertility (Fig. 11, lower part).

For the 1969 and 1973 cohorts, the graph illustrates the favourable constellation of the stabilised cumulated fertility of 15 to 29 -year-olds on one hand and the increasing recuperations between the ages of 30 and 40 on the other hand (described above). As a result, the completed fertility will slightly rise. Starting with the 1974 cohort, fertility under the age of 30 dropped steadily, indicating a renewed increase in childbearing postponement. How would this decrease affect the cohort fertility?

Using Figure 11 (above) we can see the extent of recuperation that would be necessary in specific ages to compensate for the dropping fertility among the younger fertile age and reach the completed fertility rate of 1.6. This objective would not be reached until the 1980 cohort if the recuperation trends of the past 16 years were to continue in a linear way (cf. dashed lines). This scenario does not seem unrealistic at first glance. But when we look closer, it becomes apparent that this is in fact a major challenge. On one hand, there are signs that recuperation tends to stagnate until the age of 35 in the case of Western Germany. The linear trend extrapolation used here is therefore already an optimistic assumption. On the other hand, such a shift in the cohort fertility rate to a higher childbearing age would mean that fertility at the ages of 36 to 40 years would have to increase by 250 percent between the 1962 and 1984 cohorts and recuperation at ages of 36 and older would have to equal that of the strong fertile period between 30 and 35 years of age. 
Fig. 11: Absolute changes of the age-specific cumulative cohort fertility rate (CFR) in the postponement and recuperation phase in comparison to the cohort of 1962

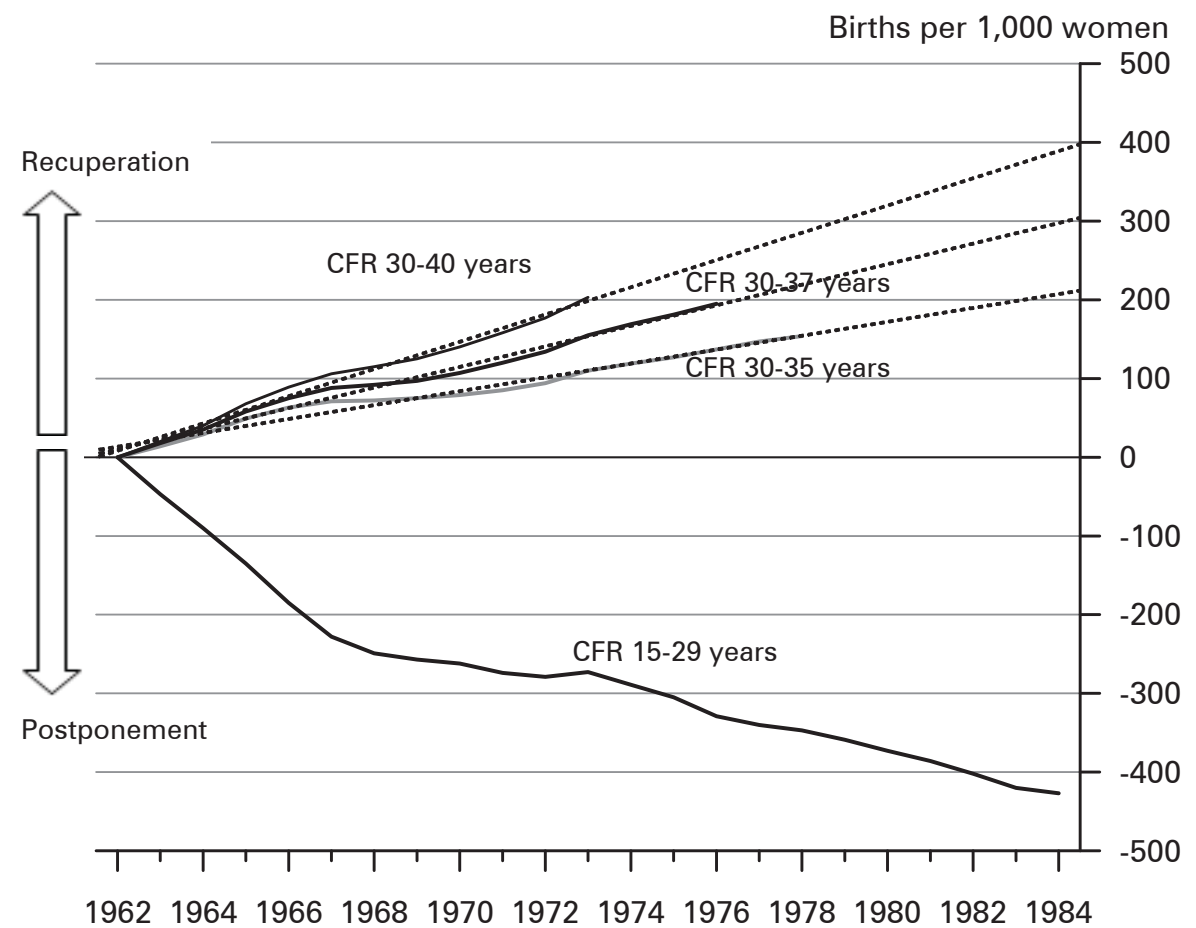

Residual deviance at the age of 40. Estimated figures for the 1974 and later cohorts with a formal extrapolation of the recuperation trend

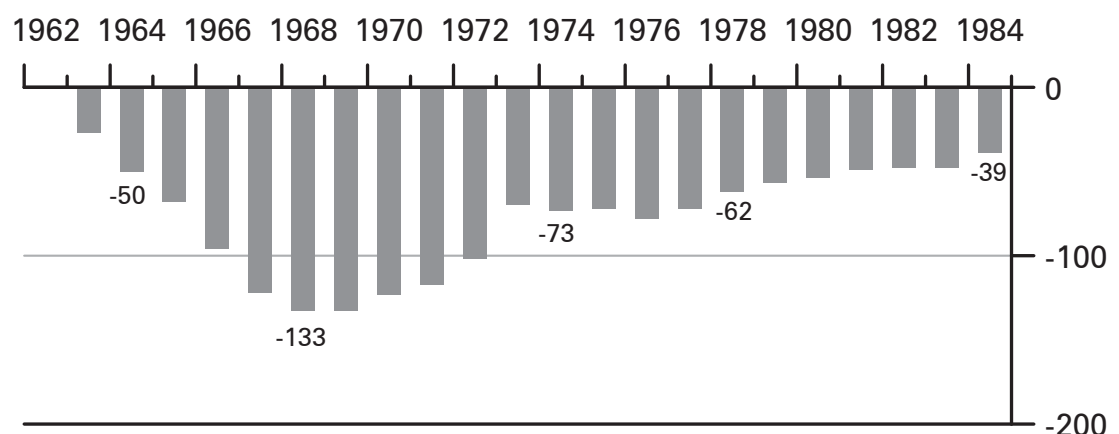

Note: CFR $x$ to $(x+n)$ years is the total age-specific fertility rate of a cohort in the respective ages. Absolute changes have been calculated as the difference between the CRF of cohort $\mathrm{c}$ and the CFR of cohort 1962 for the respective age range. The dotted line shows the linear trend.

Source: Statistisches Bundesamt, Births statistics, own calculations and design 
To stabilise the completed fertility rate at the relatively low level of 1.5 to 1.6 births per woman would require that the fertility rate of the late 1970s and 1980s cohorts rise continuously from the age of 30 onwards. With regard to parity, this means both more first births at older fertile ages and an even distribution of mothers according to number of children in spite of later family formation. Actually, the completed fertility rate of 1.6 births per woman is only reached when about 80 percent of the women of one cohort bear an average of two children. In the following, we will determine the extent to which these conditions can be fulfilled.

\subsection{Stability of the fertility rate per woman is fragile}

Between the 1930s and 1940s cohorts the average fertility rate per mother dropped from 2.3 to 2.0 and then stabilised at that level. During the decrease, the percentage of mothers with four or more children dropped from 12 percent to 6 percent. Between the late 1940s and early 1970 s cohorts the parity distribution of mothers exhibited only minor fluctuations. By 2012, 31 percent of the 45 to 49 -year-old mothers had one child, 48 percent had two children, 15 percent had three children and 6 percent four or more children. On average, mothers had two children in the course of their lives (Statistisches Bundesamt 2015c).

However, given the long-term trend towards an older age at first birth the stability of the mothers' parity distribution among the younger cohorts is at risk. This is mainly due to the fact that the share of those mothers who start a family before their thirtieth birthday is gradually getting smaller. But these were the mothers who would potentially have had many children: The microcensus survey showed for the 1960s and 1970s cohorts that on average, the more children a woman has had during her lifetime, the younger she was at the birth of her first child (Statistisches Bundesamt 2015: 30). The mothers of only children had their child on average at the age of 30 . The mothers of two children were already three years younger when they began family formation at the age of 27 . On average, mothers under the age of 25 formed families with three or more children. ${ }^{3}$ Therefore, a future stable parity distribution requires that the fertility behaviour at an older fertile age changes by increasing the percentage of mothers who start a family during their thirties and then nevertheless have three or more children.

Since the fertile window is limited, the spacing between a mother's births would also have to be shorter. This is also confirmed by the results of the microcensus. The older a mother with at least three children was at the time of the first birth, the shorter were the intervals between her births. For women who had their first child at the age of 20 , the interval between the first and third child was a little under 10

3 These microcensus results refer to mothers who were between the ages of 35 and 44 at the time of the microcensus survey in 2012 and who lived in the same household with their children. Using this method, the average age at first birth may tend to be a bit too high since in some cases the oldest child may already have moved out of the mother's household (Source: microcensus 2012, author's calculations). 
Fig. 12: Average spacing between the first and the third birth, according to the mother's age at first birth*

in years

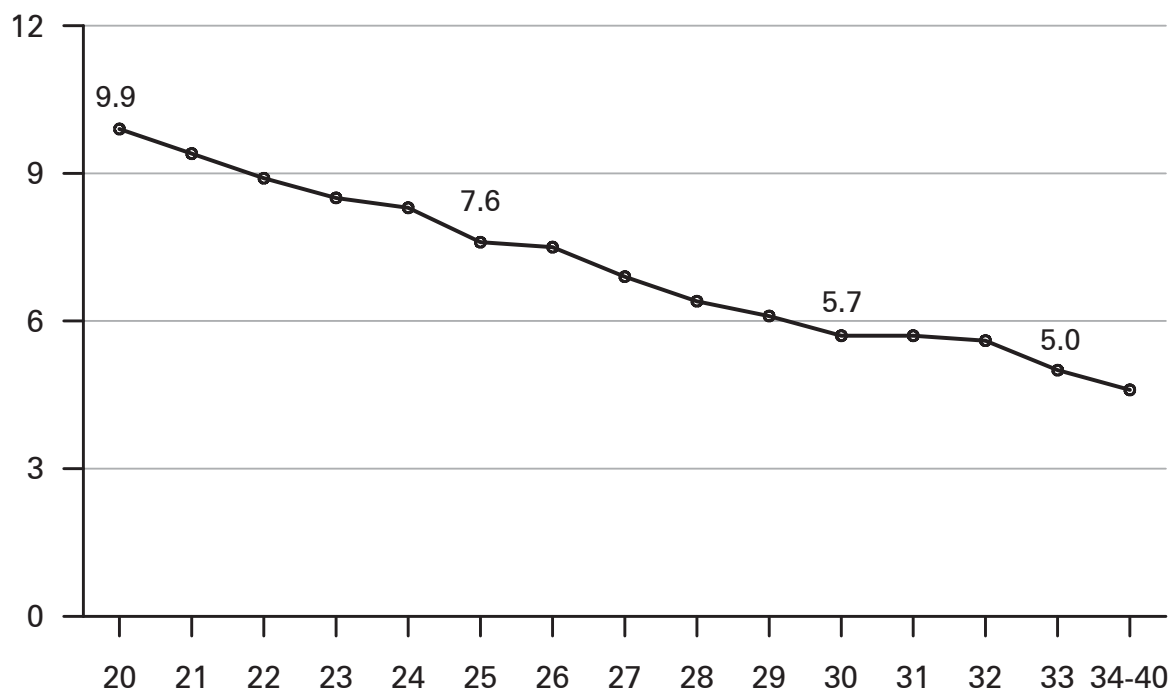

* Includes mother between 35 and 44 years with (at least) 3 children who live together in one household

Source: Statistisches Bundesamt, Microcensus 2012 (census adjusted projection), own calculations and design

years (Fig. 12). Among women who did not have their first child until they reached the age of 33 , this interval was 5 years which is only half as long. On average, 7.4 years passed between the first and third birth.

Since an increasing number of women do not become mothers until their early thirties and, if they have more than one child, they consequently have shorter birth intervals, then the median spacing should also tend to be shorter. However, the analysis of birth intervals to the previous child of a mother at her second, third or subsequent births so far does not confirm this assumption. The information about the completed birth order of mothers available since 2009, reveal instead that the median intervals between births remained unchanged from 2009 until 2014 - in spite of the continued postponements of family formation. "In 50 percent of cases a second child is born within 3.3 years after the firstborn. The other 50 percent of second born children have a further spacing to their older siblings. The third children usually follow at an even greater interval after the birth of the second child. Half of all third births take place within 3.9 years, the other half even later." (Statistisches Bundesamt 2014, quotation translated by CPoS). These results also confirm the findings of the 2012 microcensus, according to which the interval between the first and third birth is greater than 7 years on average. Consequently, mothers of three or more children are still largely starting their family early. The percentage of women 
Fig. 13: Share of births which occurred with a respective spacing to the birth of the preceding child
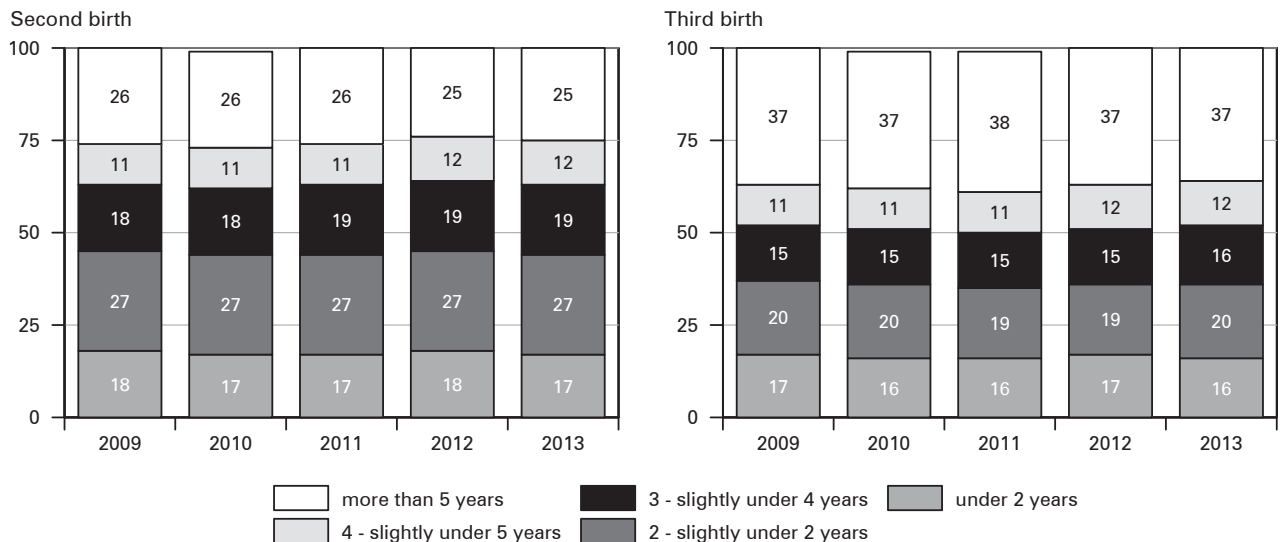

* Only one child was included in the case of giving birth to twins or multiples.

Source: Statistisches Bundesamt, Births statistics, own calculations and design

who have their first child relatively late within their fertile period is apparently low among mothers of three or more children. Therefore the distribution of birth spacing is hardly influenced by shorter intervals between their births.

The development of the intervals between births is an important early indicator of whether not only the first and second, but also subsequent births are "recuperated." As Figure 13 shows, the percentage of second or third children born within 2 years after the mother's previous child remained steady at about 16 percent to 18 percent between 2009 and 2013. About 44 percent of second and approx. 36 percent of third children were born at an interval of under 3 years. It is also worth noting that the percentage of second children born at an interval of 2 to under 3 years after the firstborn was almost exactly as large as the percentage of second children born after an interruption of five and more years. Until the third birth the intervals tended to be even greater: 37 percent of third children in 2013 were at least five years younger than the previous sibling.

Present fertility behaviour results from a combination of the trend towards late family formation, large birth intervals as well as the negative correlation between the time of the first birth and the total number of children. If this constellation does not change in the near future, it would result in a decrease in the percentage of mothers with three or more children.

\subsection{Trend towards higher childlessness continues}

Within the past twenty years, the development of the cohort fertility rates was greatly influenced by the rise in childlessness - especially in Western Germany (Statistisches Bundesamt 2013). According to Sobotka's calculations, the complet- 
ed fertility of the 1965 cohort would be 1.7 births per woman instead of 1.5 if the rate of childlessness had remained at the level of the 1940 cohort (Sobotka 2011: 273). Childlessness is also increasing in Eastern Germany, where the share of childless women was only 11 percent until the 1960s cohorts, just half as high as in Western Germany.

From the age of 41 years onwards the rate of childlessness is hardly changing. Although the number of over 40-year-olds who have a second or third child is increasing, it is still very rare for women to have their first child when they are over 40. In 2013, only 3 percent of firstborns were children of women aged between 40 and 49, and only 1 percent from the age of 42 onwards. A comparison of the rate of childlessness in the respective female cohorts between the 2008 and 2012 microcensus surveys also only shows marginal changes from the age of 39 years with the exception, however, of women with university degrees, whose family formation phase may last longer (Statistisches Bundesamt 2013: 22 and 36).

In the 1971 cohort, who reached the age of 41 in 2012, 22 percent of women remained childless. The rate of childlessness was therefore 10 percentage points higher than in the 1940 to 1946 cohorts (12 percent). Between the 1946 and 1971 cohorts, the increase in childlessness was almost linear, with the exception of some minor fluctuations (Fig. 14).

The extent to which and how long the final level of childlessness will rise in the future remains to be seen. On one hand, there are positive stimuli, for example among Western German women with academic degrees. Their final rate of childlessness recently stabilised at 29 percent and will probably even drop somewhat in the coming years (Statistisches Bundesamt 2013: 37; Statistisches Bundesamt 2015a). On the other hand, some findings indicate that the peak of the childlessness has not yet been reached. This includes, for instance, the rising percentage of women with academic degrees who exhibit above average levels of childlessness. In Eastern Germany as well as among Western German women without higher educations, childlessness will probably increase in the coming years. This would lead to a further overall increase of the childlessness level.

Socioeconomic, biomedical and cultural factors also indicate a continuation of the trend rather than a reversal. With the introduction of parental leave benefits and the expansion of childcare, family policy measures were taken that might work against this trend (Bonin et al. 2013), however, they are nowhere near solving the problem of reconciling work and family life (Bujard/Lück 2015a). For biomedical reasons, continuing to postpone the birth of the first child additionally leads to more women not being able to realise their desire for at least one child (Beier et al. 2012; te Velde et al. 2012). At the same time, the latest research on family-related role models shows that lifelong childlessness has become an appealing way of life and is "hardly ever perceived as a shortcoming anymore" (Dorbritz/Diabaté 2015: 131, translated by CPoS). 
Fig. 14: Share of childless women by the respective birth cohort, aged between $41^{*}$ and 69 years in 2012 (in \%)

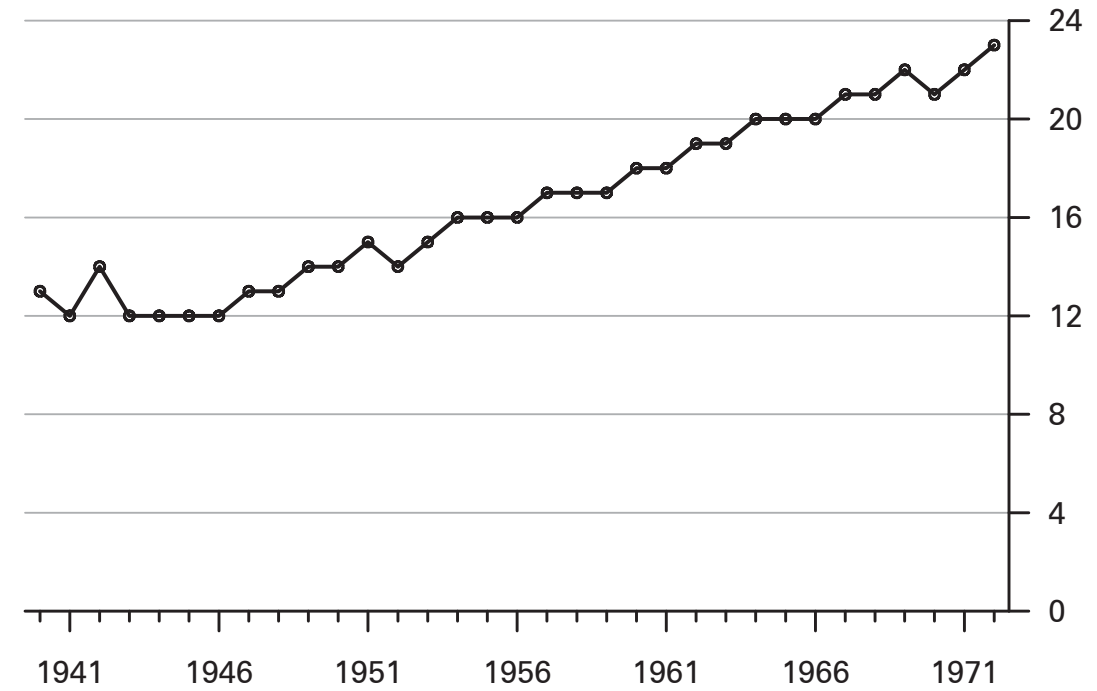

* From the age of 41 childlessness rates only marginally change.

Source: Statistisches Bundesamt, Microcensus 2012 (census adjusted projection), own calculations and design

\section{Conclusions and discussion}

The comparison of the main indicators revealed that the fertility development after the 2011 census essentially remained the same. The previous fertility trends are therefore a reliable starting point for assumptions on future developments of fertility. These considerations are not only relevant to research; the future annual fertility rate also has a real effect on the number of births and thus on population development. Given a total fertility rate of about 1.4 births per woman, a distinct decline in the number of births in the near future is predestined on the basis of the present age structure of the female population (Statistisches Bundesamt 2013: 11-14). From 2017 onwards, the decreasing 1990s and younger cohorts will reach their most fertile age during the mid-twenties to mid-thirties. The declining number of potential mothers will probably only partly be compensated by net immigration. ${ }^{4}$ Based on the results

4 In 2013, the difference between the number of 30-year-olds and 10-year-olds was 150,000 . With a positive net migration and a low mortality rate, the number of girls who are 10 years old will increase over the next 20 years. However, even given the high migration assumption of the 13th Coordinated Population Projection, they would rise by a maximum of 60,000 . Thus the number of 30 -year-old potential mothers in 2033 would still be smaller by 90,000 in comparison to 2013 (Statistisches Bundesamt. 13 $3^{\text {th }}$ coordinated population projection). 
of the $13^{\text {th }}$ Coordinated Population Projection, a relatively steady numbers of births could only be reached if, in addition to a higher net immigration rate, the annual total fertility rate would rise to at least 1.6 births per woman (Statistisches Bundesamt 2015a: Variant 6 "Relatively young population").

For this, the completed fertility would have to rise to at least 1.6 births per woman and then stabilise. The previous projections showed a probable stabilisation of the cohort total fertility rate among the cohorts of the late 1970 s at a level slightly below 1.6 (Myrskylä et al. 2013; Statistisches Bundesamt 2015a). In order to be able to assess how probable a further increase in the cohort fertility rate would be, we studied the trends in the fertility behaviour of the female cohorts. The focus was on the effects of increasing postponement of the first birth on the total cohort fertility rate. "In the latter part of the $20^{\text {th }}$ century and early in the $21^{\text {st }}$ century, the most prominent demographic mechanism determining fertility trends has been the extent to which childbearing postponement has been counterbalanced by birth recuperation." (Frejka/Sobotka 2008: 30). The experiences in France and Sweden, for example, revealed that a rising first birth age does not necessarily lead to a decline in completed fertility. However, in the case of Germany, these developments were apparently also associated with changing attitudes towards family (Ehmer et al. 2012). While the average age at first birth rose since the cohort of 1947 onwards (Pötzsch/Sommer 2009), the completed fertility rate per woman dropped from 1.80 (1946 cohort) to 1.57 (1964 cohort). The postponement of entry into parenthood was accompanied by a rapid rise in childlessness (from 12 percent to 20 percent) as well as by a decreasing percentage of women with 3 or more children, from 21 percent to 17 percent (Bujard/Lück 2015b, Table 1).

To prevent the completed fertility rate from falling in spite of childbearing postponement, the decrease in fertility at a younger age would need to be compensated or overcompensated by the recuperation of births. Using postponement and recuperation analysis, we were able to gain insights into the interaction effects of the age-specific fertility of younger cohorts up to 1984. This allows us to explain the expected slight recovery of the completed fertility rate among the 1969 to 1973 cohorts. This recovery is due to a special constellation: the birth rate of these cohorts stabilised at a younger age below 30 years, while it continually rose from the age of 30 onwards. In contrast, it becomes apparent that fertility among under-30-yearolds from the 1974 cohort again drops steadily, which results in another rise in childbearing delay.

This fertility decline at a younger age can only be compensated if the recuperation trends of the past 16 years would continue in a linear way. In addition to a significant rise in births between the ages of 30 and 35 , which appears consistent and realistic, this also means that fertility at the age of 36 and older would need to increase significantly. From today's perspective this is a very optimistic assumption. There are still "reserves" in fertility at older childbearing ages. For instance, the fertility rate of the over 36-year-olds in Germany as a whole is 26 percent lower than, for example, in Hamburg (Statistisches Bundesamt 2015d) and about 12 percent lower than in Sweden, the country with the oldest average childbearing age in Europe (Eurostat 2015: http://ec.europa.eu/eurostat/data/database). Furthermore, 
Goldstein et al. point out improved family policy frameworks, greater acceptance of female employment and the rising family focus of younger birth cohorts as factors that could result in a reversal of the trend (Goldstein et al. 2012). Although these factors apparently have a positive effect on fertility development at older childbearing ages, at the same time other findings limit the extent of the compensation effects starting at the age of 36 .

In particular, the transition to the first child during the last third of the childbearing period is still rare. According to Beier et al. the ideal time for a first pregnancy is - from the biological point of view - still between 18 and 30 years of age (Beier et al. 2012: 303). Afterwards the probability of first pregnancy gradually decreases. It remains to be seen how further medical advances will be reflected in the age-specific figures concerning first births in the future. With regard to family size, Neyer et al. reach the following conclusions: "Regarding third births, there is a relatively uniform picture: in all the Nordic countries the tendency of mothers with two children to have a third decreases with increasing age, [...]. [...] the relative risk of a second birth only drops significantly for mothers from their mid-thirties. For these mothers we can assume that at least some of them did not have another child owing to decreasing fertility although they still wanted a child" (Neyer et al. 2006; quotation translated by CPoS). In addition, the results presented show that mothers with several children are a special group. It is characteristic for them to have their first child before their mid-twenties and have relatively large intervals between individual births. In order for the percentage of mothers with three or more children to remain stable in the future, these patterns in fertility behaviour would have to change: more women who first started a family at the age of 30 and older would have to have third and subsequent children and/or the age at first birth would need to remain stable. Empirically these changes cannot yet be ascertained.

Increasing childlessness is another obstacle. To achieve and maintain the completed fertility rate per woman of at least 1.6 - with the average number of children per mother of 2.0 - the childlessness rate should not exceed 20 percent. In 2012, the rate of childlessness, however, was already 22 percent and the peak has probably not yet been reached. Despite some positive stimuli such as a consolidation of childlessness among highly educated women, there are no indications for a reversal of the increasing trend.

All in all, we can say that even the stabilisation of the completed fertility rate on a relatively low level between 1.5 and 1.6 births per woman requires that the increase in the fertility of the 1970 s and 1980 s cohorts over the age of 30 must be sufficiently strong to compensate for the increasing fertility decline under the age of 30 . To achieve this, the fertility behaviour of women would both have to change in the transition to the first child and with respect to family size. The positive momentum in the fertility rate in recent years is insofar consistent and shows that the recuperation process has intensified. An increase and subsequent stabilisation of the total cohort fertility rate at the level of at least 1.6 births per woman, however, would also require a stable fertility below the age of 30 and a decline in the childlessness rate. 


\section{Acknowledgements}

The author would like to thank Felix zur Nieden, Bettina Sommer, Martin Bujard, Norbert F. Schneider and two anonymous reviewers for their helpful comments regarding earlier versions of this article.

\section{References}

Beier, Henning M. et al. 2012: Medizinische und biologische Aspekte der Fertilität. In: Stock Günter et al. (Eds.): Zukunft mit Kindern: Fertilität und gesellschaftliche Entwicklung in Deutschland, Österreich und der Schweiz. Frankfurt am Main: Campus: 294-310.

Bongaarts, John; Feeney, Griffith 1998: On the quantum and tempo of fertility. In: Population and Development Review 24,2: 271-291.

Bongaarts, John; Sobotka, Tomas 2012: Demographic explanation for the recent rise in European fertility. In: Populaltion and Development Review 38,1: 83-120 [doi: 10.1111/j.1728-4457.2012.00473.x].

Bonin, Holger et al. 2013: Lehren für die Familienpolitik: Zentrale Resultate der Gesamtevaluation familienbezogener Leistungen [URL: ftp://ftp.zew.de/pub/zew-docs/ gutachten/Fampolit_Leistungen_HBO.pdf, 14.01.2016].

Bujard, Martin; Lück, Detlev 2015a: Kinderlosigkeit und Kinderreichtum: Zwei Phänomene und ihre unterschiedlichen theoretischen Erklärungen. In: BiB Working Paper 2015,1. Wiesbaden: Bundesinstitut für Bevölkerungsforschung [URN: urn:nbn:de:bibwp-2015-011]

Bujard, Martin; Lück, Detlev 2015b: Kinderlosigkeit und Kinderreichtum: Gründe und Daten für eine paritätsspezifische Fertilitätsforschung. In: Zeitschrift für Familienforschung 3,27: 255-269

Dorbritz, Jürgen; Ruckdeschel, Kerstin 2007: Kinderlosigkeit in Deutschland - Ein europäisches Sonderweg? Daten, Trends und Gründe. In: Kreyenfeld, Michaela; Konietzka, Dirk (Eds.): Ein Leben ohne Kinder. Wiesbaden: VS Verlag für Sozialwissenschaften: 45-82.

Dorbritz, Jürgen; Diabaté, Sabine 2015: Leitbild und Kinderlosigkeit: Kulturelle Vorstellungen zum Leben ohne Kinder. In: Schneider, Norbert F.; Diabaté, Sabine; Ruckdeschel, Kerstin (Eds.): Familienleitbilder in Deutschland. Verlag Babara Budrich: 113132.

Ehmer, Josef; Ehrhardt, Jens; Kohli, Martin 2012: Fertilität in historischer Perspektive. In: Stock, Günter et al. (Eds.): Zukunft mit Kindern. Frankfurt/New York: Campus Verlag: 41-52.

Eurostat 2015: [URL: http://ec.europa.eu/eurostat/data/database, 14.01.2016].

Frejka, Tomas; Calot, Gérard 2001: Cohort Reproductive Patterns in Low-Fertlity Countries. In: Population and Development Review 27,1 [doi: 10.1111/j.17284457.2001.00103.x].

Frejka, Tomas; Sobotka, Tomáš 2008: Overview Chapter: Fertility in Europe: Diverse, delayed and below replacement. In: Demographic Research 19,3 [doi: 10.4054/DemRes.2008.19.3].

Frejka, Tomas 2012: Die Auswirkungen des aktuellen Aufschubs und Nachholens von Geburten auf die Ausprägung der Periodenfertilitätstrends. In: Comparative Population Studies 36,4 [doi: 10.4232/10.CpoS-25011-20de]. 
Goldstein, Joshua R.; Sobotka, Tomáš; Jasilioniene, Aiva 2009: The end of 'lowest-low' fertility? In: Population and Development Review 35,4: 663-699 [doi: 10.1111/j.17284457.2009.00304.x].

Goldstein, Joshua R.; Kreyenfeld, Michaela 2011: Has East Germany overtaken West Germany? Recent trends in order-specific fertility. In: Population and Development Review 37,3: 453-472 [doi: 10.1111/j.1728-4457.2011.00430.x].

Goldstein, Joshua R. et al. 2011: Fertility Forecasting in the German-speaking World: Recent Experience and Opportunities for Improvement. In: Comparative Population Studies 36,2-3: 661-692 [doi: 10.4232/10.CPoS-2011-09en].

Goldstein, Joshua R.; Kreyenfeld, Michaela; Rößger, Felix 2012: Gibt es eine Trendumkehr in der Kinderzahl nach Geburtsjahrgängen in Deutschland? Working Paper: Berliner Demografie Forum, Ausgabe 4, Januar 2012.

Kreyenfeld, Michaela et al. 2010: Order-Specific Fertility Rates for Germany: Estimates from Perinatal Statistics for the Period 2001-2008. In: Comparative Population Studies 35,2: 207-224 [doi: 10.4232/10.CPoS-2010-06en].

Kreyenfeld, Michaela et al. 2012: Fertilitätsdaten für Deutschland, Österreich und die Schweiz: Wo liegen die Möglichkeiten? Was sind die Begrenzungen? In: Comparative Population Studies 36,2-3: 381-416 [doi: 10.4232/10.CPoS-2011-06de].

Konietzka, Dirk; Kreyenfeld, Michaela 2013: Kinderlosigkeit in Deutschland. Theoretische Probleme und empirische Ergebnisse. In: Konietzka, Dirk; Kreyenfeld, Michaela (Eds.): Ein Leben ohne Kinder: Ausmaß, Strukturen und Ursachen der Kinderlosigkeit. 2. Auflage. Wiesbaden: VS Verlag für Sozialwissenschaften.

Kohler, Hans-Peter; Ortega, José A. 2002: Tempo-adjusted period parity progression measures, fertility postponement and completed cohort fertility. In: Demographic Research 6,6: 91-144 [doi: 10.4054/DemRes.2002.6.6].

Luy, Marc 2010: Tempo-Effekte und ihre Bedeutung für die demografische Analyse. In: Comparative Population Studies 35,3: 447-482 [doi: 10.4232/10.CPoS-2010-11de].

Luy, Marc; Pötzsch, Olga 2010: Estimates of the Tempo-adjusted Total Fertility Rate in Western and Eastern Germany, 1955-2008. In: Comparative Population Studies 35,3: 569-604 [doi: 10.4232/10.CPoS-2010-14en].

Luy, Marc 2016: Demografische Kennziffern und Methoden. In: Niephaus, Yasmin; Kreyenfeld, Michaela; Sackmann, Reinhold (Eds.): Handbuch Bevölkerungssoziologie. Springer VS Verlag, Wiesbaden 2016.

Myrskylä, Mikko; Goldstein, Joshua R.; Cheng, Alice Yen-Hsin 2013: New Cohort Fertility Forecast for the Developed World: Rises, Falls, and Reversals. In: Population and Development Review 39,1: 31-56 [doi: 10.1111/j.1728-4457.2013.00572.x].

Neyer, Gerda R. et al. 2006: Fertilität, Familiengründung, Familienerweiterung in den nordischen Ländern. In: MPIDR Working Paper WP 2006-022 [http://www.demogr. mpg.de/papers/working/wp-2006-022.pdf, 15.01.2016].

Pötzsch, Olga; Sommer, Bettina 2009: Generatives Verhalten der Frauenkohorten im langfristigen Vergleich. In: Wirtschaft und Statistik 5/2009. Statistisches Bundesamt: Wiesbaden.

Pötzsch, Olga 2010a: Annahmen zur Geburtenentwicklung in der 12. koordinierten Bevölkerungsvorausberechnung. In: Wirtschaft und Statistik 1/2010. Statistisches Bundesamt.

Pötzsch, Olga 2010b: Kohortenfertilität: Ein Vergleich der Ergebnisse der amtlichen Geburtenstatistik und der Mikrozensuserhebung 2008. In: Comparative Population Studies 35,1: 165-184 [doi: 10.4232/10.CPoS-2010-05de]. 
Pötzsch, Olga 2013: Wie wirkt sich der Geburtenaufschub auf die Kohortenfertilität in West und Ost aus? In: Wirtschaft und Statistik 2/2013. Statistisches Bundesamt.

Prioux, France; Mazuy, Magali; Barbieri, Magali 2010: Recent demographic developments in France: fewer adults live with a partner. In: Population-E 65,3: 363-414 [doi: 10.1353/pop.2010.0016].

Ryder, Norman 1980: Components of temporal variations in American fertility. In: Hiorns, Robert W. (Ed.): Demographic Patterns in Developed Societies. London: Taylor and Francis: 15-54.

Sobotka, Tomáš 2003: Tempo-Quantum and Period-Cohort Interplay in Fertility Changes in Europe: Evidence from the Czech Republic, Italy, the Netherlands and Sweden. In: Demographic Research 8,6: 151-214 [doi: 10.4054/DemRes.2003.8.6].

Sobotka, Tomáš 2011: Fertility in Austria, Germany and Switzerland: Is there a Common Pattern? In: Comparative Population Studies 36,2-3 [doi: 10.4232/10.CPoS-2011-12en].

Sobotka, Tomáš et al. 2011: Postponement and Recuperation in Cohort Fertility: Austria, Germany and Switzerland in a European Context. In: Comparative Population Studies 36,2-3 [doi: 10.4232/10.CPoS-2011-10en].

Statistisches Bundesamt 2009: Imputation von Werten bei fehlenden Angaben zur Mutterschaft und zur Zahl der geborenen Kinder im Mikrozensus 2008 [https://www. destatis.de/DE/ZahlenFakten/GesellschaftStaat/Bevoelkerung/Geburten/Methoden/ Downloads/Imputationsverfahren.html, 14.01.2016].

Statistisches Bundesamt (Ed.) 2012: Geburten in Deutschland, Ausgabe 2012. Wiesbaden.

Statistisches Bundesamt (Ed.) 2013: Geburtentrends und Familiensituation in Deutschland 2012. Wiesbaden.

Statistisches Bundesamt 2014: Pressemitteilung 434/14 vom 8.12.2014 „682 000 Kinder kamen im Jahr 2013 zur Welt".

Statistisches Bundesamt (Ed.) 2015a: Bevölkerung Deutschlands bis 2060. Wiesbaden.

Statistisches Bundesamt 2015b: Geburtenraten und Tempoeffekt: [https://www.destatis.de/DE/ZahlenFakten/GesellschaftStaat/Bevoelkerung/Geburten/GeburtenratenTempoeffekt.html, 14.01.2016].

Statistisches Bundesamt 2015c: Daten zu Geburten, Familien und Kinderlosigkeit - Ergebnisse des Mikrozensus 2012 - Tabellen mit neuer Hochrechnung anhand der $\mathrm{Be}$ völkerungsfortschreibung auf Basis des Zensus 2011 - Ausgabe 2015.

Statistisches Bundesamt 2015d: Tabellen „Altersspezifische Geburtenziffern 2014_Geburtsjahr_Länder".

Stock Günter et al. (Ed.) 2012: Zukunft mit Kindern: Fertilität und gesellschaftliche Entwicklung in Deutschland, Österreich und der Schweiz. Frankfurt 2012.

te Velde, Egbert et al. 2012: The effect of postponement of first motherhood on permanent involuntary childlessness and total fertility rate in six European countries since the 1970s. In: Human Reproduction 27, 4: 1179-1183 [doi: 10.1093/humrep/der455].

Wood, Jonas; Neels, Karel; Kil, Tine 2014: The educational gradient of childlessness and cohort parity progression in 14 low fertility countries. In: Demographic research 31,46: 1365-1416 [doi: 10.4054/DemRes.2014.31.46]. 
Olga Pötzsch ( $₫)$. Federal Statistical Office. Wiesbaden, Germany.

E-mail: olga.poetzsch@destatis.de

URL: https://www.destatis.de/EN/Homepage.html 


\section{Comparative Population Studies}

WWW.comparativepopulationstudies.de

ISSN: 1869-8980 (Print) - 1869-8999 (Internet)

Published by

Prof. Dr. Norbert F. Schneider

Federal Institute for Population Research D-65180 Wiesbaden / Germany

\section{(cc) BY-SA}

2016

\section{Managing Editor}

Frank Swiaczny

\section{Assistant Managing Editor}

Katrin Schiefer

\section{Copy Editor}

(Selected Articles in German)

Dr. Evelyn Grünheid

\section{Layout}

Beatriz Feiler-Fuchs

E-mail:cpos@bib.bund.de

\section{Scientific Advisory Board}

Paul Gans (Mannheim)

Karsten Hank (Köln)

Johannes Huinink (Bremen)

Michaela Kreyenfeld (Rostock)

Marc Luy (Wien)

Notburga Ott (Bochum)

Peter Preisendörfer (Mainz)

Nikola Sander (Groningen)

Zsolt Spéder (Budapest)

\section{Board of Reviewers}

Martin Abraham (Erlangen)

Laura Bernardi (Lausanne)

Hansjörg Bucher (Bonn)

Claudia Diehl (Konstanz)

Andreas Diekmann (Zürich)

Gabriele Doblhammer-Reiter (Rostock)

Jürgen Dorbritz (Wiesbaden)

Anette Eva Fasang (Berlin)

E.-Jürgen Flöthmann (Bielefeld)

Alexia Fürnkranz-Prskawetz (Wien)

Beat Fux (Salzburg)

Joshua Goldstein (Berkeley)

Sonja Haug (Regensburg)

Hill Kulu (Liverpool)

Aart C. Liefbroer (Den Haag)

Kurt Lüscher (Konstanz)

Emma Lundholm (Umeå)

Nadja Milewski (Rostock)

Dimiter Philipov (Wien)

Roland Rau (Rostock)

Tomáš Sobotka (Wien) Jeroen Spijker (Barcelona)

Olivier Thévenon (Paris)

Helga de Valk (Brussel)

Heike Trappe (Rostock)

Michael Wagner (Köln) 